\title{
A lei fraca de Feller para jogos de São Petersburgo
}

\author{
Rodrigo Viana Rocha
}

DissertaÇÃo Apresentada ao

Instituto DE MATEMÁtica E Estatística

Da Universidade de São Paulo

Para Obtenção do Título de

Mestre em CiênCIAS

Programa: Estatística

Orientador: Prof. Dr. Sergio Wechsler

São Paulo, março de 2009 


\section{A lei fraca de Feller para jogos de São Petersburgo}

Este exemplar corresponde à redação final da dissertação devidamente corrigida e defendida por Rodrigo Viana Rocha e aprovada pela comissão julgadora

São Paulo, 09 de junho de 2009

Banca Examinadora:

- Prof. Dr. Sergio Wechsler - (Presidente) - IME-USP

- Profa. Dra. Claudia Monteiro Peixoto - IME-USP

- Prof. Dr. Jesús Enrique Garcia - UNICAMP 


\section{Agradecimentos}

Em primeiro lugar gostaria de agradecer a Deus, à minha família, minha mãe, meu pai, meus irmãos, meus avôs e avós (principalmente avós), meus tios e tias, primos e primas e aos meus queridos amigos. Agradeço em especial à minha amada esposa, Sylvie Brigitte van Eyll Rocha, por me amar tão intensamente quanto eu a amo.

Agradeço ao meu orientador, Professor Sergio Wechsler, principalmente por ter me apresentado com maestria aos assuntos mais interessantes da Teoria de Probabilidades que, de tão fascinantes, chamam a atenção de qualquer um minimamente curioso. Agradeço sua paciência e companheirismo, sem os quais eu não poderia ter chegado até o fim deste trabalho.

Também não poderia deixar de agradecer aos meus queridos colegas do IME-USP por me ajudarem nos momentos difíceis e pela alegria proporcionada nos momentos de descontração. Um abraço especial aos amigos: Marcel Taga, Dalton Pinheiro, Rafael Farias e Alexandre Patriota.

À Professora Zara Issa Abud por ter superado todas as minhas expectativas de quão bom um mestre pode ser.

Aos professores do departamento de Estatística do IME-USP pelo valioso aprendizado: Sergio Wechsler, Mônica Sandoval, Claudia Peixoto, Gilberto Alvarenga e Carlos Alberto de Bragança Pereira. 


\section{Resumo}

Quase três séculos já se passaram desde que a primeira versão do chamado paradoxo de São Petersburgo chegou aos meios acadêmicos através do trabalho de Daniel Bernoulli. Contudo, a relevância desse assunto ainda reverbera em artigos científicos atuais em diversas áreas do conhecimento (notadamente, mas não exclusivamente, na Economia e na Estatística). Um jogo de enunciado simples cuja esperança matemática dos ganhos do jogador surpreendentemente é infinita, entretanto, dificilmente alguém estaria disposto a pagar qualquer taxa de entrada cobrada para jogá-lo.

No presente trabalho buscou-se em primeiro lugar apresentar uma análise crítica do desenvolvimento histórico das "soluções" propostas para o paradoxo. Em seguida mostrou-se uma aplicação direta do paradoxo a um modelo matemático utilizado até hoje para avaliar o preço justo de ações. Por fim, revisaram-se alguns resultados obtidos pela moderna teoria da probabilidade através da convergência em probabilidade.

Palavras-chave: Paradoxo de São Petersburgo, utilidade, lei dos grandes números 


\section{Abstract}

It has been almost three centuries since the first version of the so-called St. Petersburg Paradox has reached the academic environment through the work of Daniel Bernoulli. However, the relevance of this subject still reverberates in new scientific papers in many knowledge fields (especially, but not exclusively, in Economics and Statistics). A game with a simple rule in which the mathematical expectation of the player's gains is unexpectedly infinite but hardly someone would be willing to pay any asked entrance fee to play it.

In this work we pursued at first to present a critical analysis on the historical development of the proposed "solutions" to the paradox. After that, we showed an application of the paradox to a mathematical model, that is still in use today, to obtain a fair price of a stock share. At last we reviewed some results given by the modern probability theory through the convergence in probability.

Keywords: St. Petersburg paradox, utility, law of large numbers 


\section{Sumário}

1 Introdução $\quad \mathbf{7}$

1.1 Valor esperado e a definição de "jogo honesto" . . . . . . . . . 8

1.1.1 Probabilidade e variáveis aleatórias . . . . . . . . . 8

1.1.2 Valor esperado . . . . . . . . . . . . . . . . . . . . 10

1.1.3 Jogo honesto . . . . . . . . . . . . . . . . . 14

1.2 Definição do paradoxo . . . . . . . . . . . . . . . . . . . 14

2 Tentativas de resolver o paradoxo 16

2.1 A solução de Bernoulli . . . . . . . . . . . . . . . . . . 16

2.2 A solução de Cramer . . . . . . . . . . . . . . . . . . . 25

2.3 Soluções discutidas por Karl Menger . . . . . . . . . . . . . 27

2.3.1 A alegação de inconsistência . . . . . . . . . . . . 27

2.3.2 Solução com base no conceito frequentista de probabilidade . . . . . . . . . . . . . . . . 28

2.3.3 Soluções baseadas em funções-utilidade sem limites . . 29

2.3.4 Soluções baseadas em funções-utilidade limitadas . . . 31

2.3.5 O comportamento do apostador . . . . . . . . . . . 33

3 Aplicações do paradoxo $\quad 37$

3.1 Principal conceito de valuation . . . . . . . . . . . . 38

3.2 Fluxos de caixa e o paradoxo . . . . . . . . . . . . . 39

4 O paradoxo segundo a moderna Teoria de Probabilidades 43

4.1 Hipóteses necessárias . . . . . . . . . . . . . . . . . . . . . 43

4.2 A lei dos grandes números $(\mathrm{LGN}) \ldots \ldots . \ldots 45$ 
4.2.1 Prova da LGN pela desigualdade de Chebyshev . . . . 46

4.2.2 Prova da LGN para quando a variância não é finita . . 48

4.3 A lei dos grandes números (LGN) aplicada ao paradoxo . . . . 51

4.3.1 Prova da aplicabilidade . . . . . . . . . . . 51

4.3.2 Um jogo "honesto" mas com perdas crescentes ao jogador 53

5 Conclusão

54

Rodrigo Viana Rocha

IME-USP 


\section{Capítulo 1}

\section{Introdução}

Em 1738 Daniel Bernoulli ${ }^{1}$ apresentava ao mundo, através de trabalho publicado pela Academia Imperial de São Petersburgo, o fascinante problema que ano após ano insiste em aparecer com nova roupagem nas grandes revistas acadêmicas de diversas áreas do conhecimento como Estatística, Matemática, Economia e até mesmo Filosofia.

A crítica contundente que é ilustrada na forma do paradoxo no artigo de Daniel Bernoulli é o uso ingênuo do valor esperado como uma medida de risco de um determinado jogo. O que Bernoulli critica nesse artigo não é o uso do valor esperado propriamente dito, mas sim um uso incauto do mesmo que gera uma medida de risco que ignora completamente as preferências e a dotação inicial de recursos dos jogadores.

A força dessa argumentação é especialmente compatível com o paradigma bayesiano no sentido que corrobora com a tese de que a atribuição de utilidade, e a respectiva tomada de decisão que ela muitas vezes busca auxiliar, não pode estar sempre dissociada de parâmetros subjetivos.

Nas seções a seguir mostra-se em detalhes o processo de construção do

\footnotetext{
${ }^{1}$ Embora Daniel tenha sido o primeiro a apresentar o problema à comunidade científica em Bernoulli[1], o mesmo atribuiu a idéia original ao seu primo, Nicolas Bernoulli. A primeira vez que o problema teria sido apresentado de forma escrita foi em carta deste último a Pierre Raymond de Montmort em 09 de setembro de 1713.
} 
paradoxo.

\subsection{Valor esperado e a definição de "jogo ho- nesto"}

Antes que se esclareça o conceito de jogo honesto e como ele está intimamente ligado ao paradoxo de São Petersburgo, é conveniente nesse momento retomar as definições de probabilidade, variável aleatória e valor esperado.

\subsubsection{Probabilidade e variáveis aleatórias}

Segundo Magalhães[12] a definição clássica de probabilidade remete a subconjuntos unitários equiprováveis. Desse modo a definição para a probabilidade de ocorrência do evento $A$, que está contido num espaço amostral $\Omega$, ficaria:

$$
\operatorname{Pr}(A)=\frac{n(A)}{n(\Omega)}
$$

em que a $n(A)$ representa a cardinalidade do conjunto $A$.

Quando $\Omega$ não for enumerável, o conceito se aplica ao comprimento de intervalos, medidas de áreas ou similares, por exemplo:

$$
\operatorname{Pr}(A)=\frac{\text { comprimento }(A)}{\text { comprimento }(\Omega)}
$$

Uma outra definição, denominada frequentista ou estatística, considera o limite das frequências relativas obtidas num experimento como o valor da probabilidade. Seja $n_{A}$ o número de ocorrências do evento $A$ em $n$ repetições independentes do experimento, então:

$$
\operatorname{Pr}(A)=\lim _{n \rightarrow \infty} \frac{n_{A}}{n}
$$

Embora a definição anterior tenha grande apelo intuitivo, é importante 
notar-se alguns problemas que ela traz consigo: como se pode garantir que tal razão convergirá para um valor limitado? Ou ainda, mesmo que se possa garantir que a razão convergiu em um determinado experimento, poder-se-á garantir a convergência para um segundo ensaio automaticamente?

Defensores da definição de probabilidade frequentista poderiam tentar garantir a convergência da razão acima transformando-a numa hipótese aceita a priori, isto é, um axioma do sistema. Contudo, destarte tal hipótese parece ser complexa demais.

Nesse contexto, de busca por hipóteses mais simples e evidentes utilizadas com o objetivo de formalizar a definição de probabilidade, surgiu o conjunto dos axiomas de Kolmogorov que são apresentados a seguir utilizando o conceito de $\sigma$-álgebra.

\section{Definição de $\sigma$-álgebra}

Uma classe de subconjuntos de $\Omega$, representada por $\mathcal{F}$, é denominada uma $\sigma$-álgebra se satisfaz as seguintes propriedades:

- (A1) $\Omega \in \mathcal{F}$;

- (A2) Se $A \in \mathcal{F}$, então $A^{c} \in \mathcal{F}$;

- (A3) se $A_{i} \in \mathcal{F}, i \geq 1$, então $\bigcup_{i=1}^{\infty} A_{i} \in \mathcal{F}$.

\section{Definição formal de probabilidade}

Uma função Pr na $\sigma$-álgebra $\mathcal{F}$ de subconjuntos de $\Omega$ e com valores em $[0,1]$ é uma probabilidade se satisfaz:

- (A1) $\operatorname{Pr}(\Omega)=1$;

- (A2) Para todo subconjunto de $A \in \mathcal{F}, \operatorname{Pr}(A) \geq 0$;

- (A3) Para toda sequência $A_{1}, A_{2}, \cdots \in \mathcal{F}$, mutuamente exclusivos, 
tem-se:

$$
\operatorname{Pr}\left(\bigcup_{i=1}^{\infty} A_{i}\right)=\sum_{i=1}^{\infty} \operatorname{Pr}\left(A_{i}\right)
$$

A trinca $(\Omega, \mathcal{F}, \operatorname{Pr})$ é denominada espaço de probabilidade. Os subconjuntos de $\mathcal{F}$ são denominados eventos e é somente a eles que se atribui probabilidade.

\section{Definição de variável aleatória}

Seja $(\Omega, \mathcal{F}, \operatorname{Pr})$ um espaço de probabilidade, denomina-se variável aleatória, qualquer função $X: \Omega \rightarrow \mathbb{R}$ tal que:

$$
X^{-1}(I)=\{\omega \in \Omega: X(\omega) \in I\} \in \mathcal{F}, \quad \text { para todo intervalo } I \subset \mathbb{R} \text {. }
$$

Ou seja, uma variável aleatória é uma função que leva um elemento do espaço amostral $\omega \in \Omega$ num número real $X(\omega)$. Ao exigir que, para qualquer $I \subset \mathbb{R}$ o conjunto $X^{-1}(I)$ seja um evento, garante-se o cálculo de probabilidades.

\subsubsection{Valor esperado}

Numa definição informal, segundo Casella-Berger[2]:

O valor esperado (ou esperança) de uma variável aleatória é meramente seu valor médio. Ponderando-se os valores que a variável aleatória pode assumir de acordo com sua distribuição de probabilidade estar-se-ia tentando obter um número com a capacidade de expressar resumidamente valores típicos ou "esperados" de uma observação da variável aleatória.

De fato, de uma perspectiva mais formal, esse esboço inicial do conceito de valor esperado falha em expressar precisamente sua definição. Por exemplo, parece ser impreciso ao tentar definir o valor esperado de variáveis aleatórias contínuas (tomando-se uma variável aleatória $X$ contínua com distribuição Normal, tem-se que a mesma pode assumir valores em toda a reta real, 
todavia, a probabilidade de que ela assuma um valor determinado, diga-se $X=1$, é nula. Portanto, sabe-se que nesses casos o cálculo do valor esperado não pode ser obtido a partir de uma média ponderada simples).

Outra imprecisão surge quando se emprega o termo "valor típico", porque de fato é possível que o valor esperado de uma determinada distribuição sequer faça parte do conjunto de valores os quais a variável aleatória pode assumir (a exemplo da variável aleatória que se pode associar aos resultados do lançamento de um dado honesto: O valor esperado dessa variável é 3,5 contudo o mesmo é impossível de ser observado em qualquer lançamento).

Uma vez feitas todas essas ressalvas, qual seria um conceito intuitivo um pouco mais acertado para definir o valor esperado?

Ainda aproveitando o exemplo de um dado honesto, imagine um jogo em que um dado perfeitamente simétrico e de faces numeradas é lançado diversas vezes. Se o lado 1 é observado, o jogador ganha uma moeda; se o lado 2 ocorre, o jogador ganha duas moedas; e assim sucessivamente, podendo o jogador ganhar até seis moedas, quando o lado 6 é observado. Anotando-se num caderno o ganho obtido em diversos lançamentos do dado, observarse-á que a razão de ganho por lançamento (estimada pela soma dos ganhos anotados dividida pelo total de lançamentos) será muita próxima ${ }^{2}$ de 3,5 , isto é, muito próxima do valor esperado da variável aleatória usada para modelar o lançamento do dado.

Isso posto, parece bastante natural que, desde o começo da Teoria da Probabilidade, motivada sobretudo em quantificar as chances de ganhar ou perder em jogos de azar, o valor esperado fosse empregado intuitivamente, servindo de ferramenta para estimar ganhos em cada tipo de jogo a partir de suas regras e resultados possíveis.

Para o caso de uma variável aleatória discreta $X$, com função de probabilidade $\operatorname{Pr}(X=x)$, pode-se definir formalmente o valor esperado (ou esperança)

\footnotetext{
${ }^{2}$ De fato o que está por trás da convergência da média amostral de ensaios independentes de uma determinada distribuição para a média da distribuição, quanto maior for o tamanho da amostra, é justamente o resultado conhecido como a lei dos grandes números (LGN) que será apresentada posteriomente neste trabalho.
} 
como:

$$
E(X)=\sum_{i} x_{i} \operatorname{Pr}\left(X=x_{i}\right)
$$

este valor está bem definido quando a série converge absolutamente, isto é, $\sum_{i}\left|x_{i}\right| \operatorname{Pr}\left(X=x_{i}\right)<\infty$.

Para uma variável aleatória $X$ contínua, com função densidade dada por $f(x)$, o cálculo do valor esperado é dado por:

$$
E(X)=\int_{-\infty}^{+\infty} x f(x) d x
$$

desde que a integral esteja bem definida, isto é, $\int_{-\infty}^{+\infty}|x| f(x) d x<\infty$.

Entretanto, seria muito mais conveniente poder escrever de uma só forma a definição do valor esperado independentemente de a variável $X$ ser discreta, contínua ou, até mesmo, mista. Esse objetivo pode ser atingido utilizando-se a função distribuição $F(X)$ no lugar da função de probabilidade ou densidade e, ainda, empregando-se a integral de Riemann-Stieltjes.

De acordo com James[11], se $\varphi$ é uma função contínua definida no intervalo $[a, b]$ e $F$ é uma função de distribuição, define-se integral de Riemann-Stieltjes de $\varphi$ em $[a, b]$, em relação a $F$ (ou ponderada por $F$ ), como o limite de "somas de Riemann" da forma:

$$
\sum_{i=1}^{n} \varphi\left(y_{i}\right)\left[F\left(x_{i+1}\right)-F\left(x_{i}\right)\right]
$$

em que $a=x_{1}<x_{2}<\cdots<x_{n+1}=b, y_{i}$ é um ponto arbitrário de $\left[x_{i}, x_{i+1}\right]$ e toma-se o limite quando a norma da partição tende a zero. A partição consiste nos pontos $x_{i}$ 's e sua norma é dada por $\max _{1 \leq i \leq n}\left(x_{i+1}-x_{i}\right)$. Esse limite é representado por:

$$
\int_{a}^{b} \varphi(x) d F(x)
$$

A integral de Riemann-Stieltjes goza de diversas propriedades que, em sua maioria, também são conhecidas nas integrais de Riemann: 
- (P1) Notação: $\int \varphi d F=\int_{-\infty}^{\infty} \varphi d F=\lim _{\substack{a \rightarrow-\infty \\ b \rightarrow+\infty}} \int_{a}^{b} \varphi d F$;

- (P2) Diferencial e diferença: $\int_{a}^{b} \varphi(x) d F(x)=F(a)-F(b)$;

- (P3) Linearidade: Para $\alpha, \beta$ constantes em $x$, se $\varphi(x)=\alpha f(x)+$ $\beta g(x)$, então: $\int_{a}^{b} \varphi(x) d F(x)=\alpha \int_{a}^{b} f d F(x)+\beta \int_{a}^{b} g d F(x)$;

- (P4) Aditividade: Se $a<b<c$, então: $\int_{a}^{c} \varphi d F=\int_{a}^{b} \varphi d F+\int_{b}^{c} \varphi d F$;

- (P5) Particularidade para distribuições discretas: essa propriedade é especialmente importante para que se possa empregar a integral de Riemann-Stieltjes no cálculo da esperança. Quando $F$ é a função distribuição de uma variável aleatória discreta $X$, a integral de Stieltjes reduz-se a uma série:

$$
\int \varphi d F=\int_{-\infty}^{+\infty} \varphi(x) d F(x)=\sum_{i} \varphi\left(x_{i}\right) \operatorname{Pr}\left(X=x_{i}\right)
$$

Sabe-se que quando $\operatorname{Pr}\left(X=x_{i}\right)>0$ é porque ocorre um "salto" no ponto $x_{i}$ da função $F$ e o "tamanho" desse salto é justamente $\operatorname{Pr}(X=$ $x_{i}$ ), daí a explicação intuitiva da igualdade acima. Ademais tem-se que:

$$
\int_{a}^{b} \varphi d F=\sum_{i: a<x_{i} \leq b} \varphi\left(x_{i}\right) \operatorname{Pr}\left(X=x_{i}\right)
$$

Uma vez apresentada a definição e propriedades da integral de RiemannStieltjes, para o caso particular em que $\varphi(x)=x$ pode-se escrever uma definição mais geral de esperança da seguinte maneira:

$$
E(X)=\int_{-\infty}^{+\infty} x d F(X)=\mu
$$

quando a integral imprópria de Riemann-Stieltjes está bem definida. 


\subsubsection{Jogo honesto}

Se $X$ é a variável aleatória que representa o ganho do jogador, uma definição muito utilizada para definir um "jogo honesto" é a seguinte:

Um jogo pode ser chamado de honesto se o preço a se pagar para jogá-lo é igual a $\mu$. Em outras palavras, o jogo é honesto se depois de diversas repetições do mesmo, o ganho médio do jogador é muito próximo ao preço pago pelo mesmo para jogar.

A interpretação implícita e que orienta a decisão é que se o preço de entrada do jogo for maior do que $\mu$, possivelmente não valeria a pena jogar porque o jogador que o fizer estará, mais cedo ou mais tarde, perdendo dinheiro. Por outro lado, se o preço pago para jogar for menor do que $\mu$, no longo prazo, isto é, após várias tentativas, o jogador terá vantagem em relação à banca.

\subsection{Definição do paradoxo}

O paradoxo é costumeiramente apresentado num jogo simples realizado entre dois amigos, Pedro (a banca) e Paulo (o jogador):

Pedro lança uma moeda honesta repetitivamente até obter uma cara. Ele concorda em pagar a Paulo um real se a cara aparecer no primeiro lançamento, dois reais se ela aparecer no segundo lançamento, quatro reais se ela aparecer no terceiro lançamento, oito reais se ela aparecer no quarto lançamento e assim por diante. Quanto Pedro deve cobrar de Paulo para jogar?

A função de probabilidade:

$$
\operatorname{Pr}\{N=n\}=\left(\frac{1}{2}\right)^{n}, n=1,2,3, \ldots
$$

é de uma variável aleatória $N$ que representa em que lançamento a moeda apresentará a primeira cara. Claramente a mesma tem distribuição 
geométrica com $p=\frac{1}{2}$. A variável aleatória $X$, que representa o ganho do jogador, é na verdade uma função de $N$, isto é $X(N)$, e tem sua função de probabilidade:

$$
\operatorname{Pr}\left\{X=2^{n-1}\right\}=2^{-n}, n=1,2,3, \ldots
$$

Para avaliar a proposta de Pedro, Paulo poderia lançar mão de diversas estratégias. Entretanto, se ele resolvesse utilizar o conceito de jogo honesto visto em (1.1.3), o valor esperado de $X$ encontrado seria:

$$
\begin{aligned}
E(X) & =\int_{-\infty}^{+\infty} x \cdot d F(X)=\sum_{n=1}^{\infty} 2^{n-1} \cdot\left(\frac{1}{2}\right)^{n} \\
E(X) & =1 \cdot \frac{1}{2}+2 \cdot \frac{1}{4}+4 \cdot \frac{1}{8}+8 \cdot \frac{1}{16}+\cdots \\
& =\frac{1}{2}+\frac{1}{2}+\frac{1}{2}+\frac{1}{2}+\cdots
\end{aligned}
$$

mostrando que a esperança desse jogo é infinita.

Sob essa perspectiva, seria racional ${ }^{3}$ para Paulo pagar qualquer valor em reais para jogar?

\footnotetext{
${ }^{3}$ A palavra "racional" aqui utilizada é derivada do conceito de "agente racional", amplamente empregado em Economia, Teoria do Jogos e Teoria da Decisição, em que o agente aplica o conceito de valor esperado aos eventos aleatórios de modo a fazer escolhas que otimizem seu ganho, dentro do conjunto de escolhas possíveis.
} 


\section{Capítulo 2}

\section{Tentativas de resolver o paradoxo}

\subsection{A solução de Bernoulli}

A solução de Bernoulli[1] para o paradoxo de São Petersburgo surge num contexto muito mais amplo em que o matemático, buscando enriquecer o debate ainda incipiente acerca de medidas de risco, sugere uma mudança fundamental no conceito de valor esperado ${ }^{1}$ descrito abaixo com suas palavras e considerado por ele amplamente aceito em sua época:

Os valores esperados são calculados multiplicando-se cada possibilidade de ganho, $x$, pelo número de maneiras em que esse ganho possa ocorrer e dividindo-se a soma desses produtos pelo número total de casos possíveis.

$$
E(X)=\frac{n_{1} x_{1}+n_{2} x_{2}+\cdots}{n_{1}+n_{2}+\cdots}
$$

\footnotetext{
${ }^{1}$ Note-se que essa definição de esperança é precária com relação àquela já apresentada em (1.3) pois foi feita no século XVIII.
} 
Dessa forma, quem quer que seja o jogador, desde que seja capaz de ponderar adequadamente as possibilidades, obterá do valor esperado sempre a mesma percepção do risco embutido em cada jogo. Contudo, seria essa uma propriedade desejável?

Note-se o que tinha Bernoulli[1] a argumentar a respeito:

Para tornar esse ponto de vista mais claro, seria recomendável tomar o seguinte exemplo: Imagine um sujeito paupérrimo que encontra um bilhete de loteria que pagará, com igual probabilidade, nada ou duzentos mil reais ${ }^{2}$. Esse homem avaliaria sua perspectiva de ganhar em cem mil reais? Seria um mal conselho propor-lhe vender o bilhete por noventa mil reais? Eu penso que não. Por outro lado, estou inclinado a acreditar que um homem rico que se negasse a comprar o bilhete de loteria por noventa mil reais estaria sendo mal aconselhado.

Claramente, para Bernoulli, os instrumentos matemáticos para a avaliação de risco não poderiam estar dissociados da dotação inicial de recursos, tampouco do grau de aversão ao risco de cada jogador. No entanto, abdicar completamente do conceito de valor esperado parecia-lhe imprudente, ao passo que, como dito anteriormente, era um método bastante intuitivo, amplamente aceito e com a pretenção de tornar comparável os diferentes riscos sob os quais se expunham os jogadores.

A forma encontrada pelo o matemático para resolver essa questão foi a seguinte. Onde na proposição acima lia-se a palavra "ganho", e que normalmente entendia-se como o lucro ou prejuízo auferido pelo jogador em cada caso, dever-se-ia substituí-la pela palavra utilidade que aquele determinado caso traria ao jogador.

Enquanto mil reais significam o mesmo valor financeiro tanto para um indivíduo pobre ou rico, a utilidade ${ }^{3}$ desse dinheiro é geralmente muito maior

\footnotetext{
${ }^{2}$ Originalmente o texto fala em vinte mil ducados que eram moedas cunhadas em ouro usadas como meio de troca na Europa antes da Primeira Guerra Mundial.

${ }^{3}$ Para muitos historiadores, Bernoulli inaugarava com esse artigo o conceito econômico fundamental de utilidade.
} 
para o primeiro do que para o segundo. É evidente que o conceito de utilidade que aos poucos tomava forma nessas palavras de Bernoulli buscava ser o mais abrangente possível, ou o que melhor expressava a natureza humana como um todo, e, portanto, sujeito a exceções. O próprio Bernoulli advertiu que para um homem mais "generoso" um real significava menos do que ele poderia significar para outro homem, mesmo sendo o primeiro homem mais pobre do que o segundo. Contudo, ele elegantemente definiu o conceito mais geral de utilidade através de dois axiomas extremamente simples e aceitáveis que mais adiante nortearam a construção de sua função de utilidade esperada:

- Qualquer aumento na riqueza de um indivíduo, não importando o quão pequeno ele seja, resultará num aumento de utilidade;

- A utilidade resultante de qualquer pequeno aumento na riqueza do indivíduo é inversamente proporcional a quantidade de bens que o indivíduo já possuía antes.

Bernoulli expressou matematicamente tais hipóteses da seguinte forma:

Seja $u(x)$ uma função utilidade, dependente da riqueza $x$ do indivíduo, então uma variação infinitesimal na utilidade, $d u$, será diretamente proporcional a uma variação infinitesimal na riqueza do indivíduo, $d x$, e inversamente proporcional à sua riqueza inicial $x$, matematicamente:

$$
d u=b \cdot \frac{d x}{x}, \text { em que } b \text { é uma constante arbitrária }
$$

Pode-se reescrever (2.2) como:

$$
u=b \cdot \log \left(\frac{x}{\alpha}\right), \text { em que } b>0 \text { e } \alpha>0 \text { são constantes arbitrárias }
$$

Seja a função utilidade esperada escrita na forma:

$$
E(U)=\frac{n_{1} u_{1}+n_{2} u_{2}+\cdots}{n_{1}+n_{2}+\cdots}
$$


E seja $\hat{x}$ a riqueza ${ }^{4}$ tal que gera a utilidade esperada $E(U)$, então de (2.3), tem-se que:

$$
\begin{aligned}
b \cdot \log \left(\frac{\hat{x}}{\alpha}\right) & =\frac{n_{1} \cdot b \cdot \log \left(\frac{x_{1}}{\alpha}\right)+n_{2} \cdot b \cdot \log \left(\frac{x_{2}}{\alpha}\right)+\cdots}{n_{1}+n_{2}+\cdots} \\
\log \left(\frac{\hat{x}}{\alpha}\right) & =\log \left(\frac{x_{1}}{\alpha}\right)^{\frac{n_{1}}{n_{1}+n_{2}+\cdots}}+\log \left(\frac{x_{2}}{\alpha}\right)^{\frac{n_{2}}{n_{1}+n_{2}+\cdots}}+\cdots \\
\frac{\hat{x}}{\alpha} & =\cdot\left(\frac{x_{1}}{\alpha}\right)^{\frac{n_{1}}{n_{1}+n_{2}+\cdots}} \cdot\left(\frac{x_{2}}{\alpha}\right)^{\frac{x_{2}}{n_{1}+n_{2}+\cdots}} \cdots \\
\frac{\hat{x}}{\alpha} & =\left(\frac{1}{\alpha}\right) \cdot\left(x_{1}\right)^{\frac{n_{1}}{n_{1}+n_{2}+\cdots}} \cdot\left(x_{2}\right)^{\frac{x_{2}}{n_{1}+n_{2}+\cdots}} \cdots \\
\hat{x} & =\left(x_{1}^{n_{1}}+x_{2}^{n_{2}}+\cdots\right)^{1 /\left(n_{1}+n_{2}+\cdots\right)}
\end{aligned}
$$

ou numa linguagem matemática mais conteporânea:

$$
\hat{x}=\left(x_{1}\right)^{p_{1}} \cdot\left(x_{2}\right)^{p_{2}} \cdots
$$

em que $p_{i}$ é a probabilidade do evento $i=1,2, \cdots$.

Um exemplo interessante apresentado por Bernoulli dessa maneira de pensar o valor esperado é o seguinte:

Suponha que dois jogadores, ambos com cem reais inicialmente, colocam metade do que possuem num jogo que oferece a mesma possibilidade de ganho para cada um. De acordo com tal suposição, cada um terá cinquenta reais garantidos mais uma expectativa de ganhar cem reais a mais. Pela regra (2.5), o ganho equivalente desse jogo seria de $\left(50^{1} \cdot 150^{1}\right)^{1 / 2}$ ou $\sqrt{50 \cdot 150}$, isto é menos de oitenta e sete reais, de tal forma que, mesmo o jogo sendo apresentado em condições perfeitamente equilibradas para ambos, existe uma perda esperada de mais de treze reais para cada um. É preciso enfatizar essa verdade, muito embora ela seja evidente: a imprudência do jogador será maior quanto maior for

\footnotetext{
${ }^{4}$ Bernoulli teria considerado $\hat{x}$ como o próprio valor esperado de $X$. Porém, é fácil ver que $E(U) \neq b \cdot \log \left[\frac{E(X)}{\alpha}\right]$.
} 
a parte de sua fortuna que será exposta a um jogo de azar. Modificando o exemplo anterior, se cada jogar iniciasse com duzentos reais, e ainda apostasse cinquenta reais, a perda esperada do jogo seria então $200-\sqrt{150 \cdot 250}$ que é pouco mais de seis reais.

Fica evidente na passagem supracitada uma das principais características da função utilidade esperada de Bernoulli: a hipótese que, de maneira geral, os indivíduos são avessos ao risco. Um importante passo fora dado na tentativa de modelar racionalmente o comportamento humano nas tomadas de decisão. Mas como tal função seria capaz de, ao mesmo tempo, resolver (ao menos temporariamente) o problema do paradoxo? 
Com intuito de responder a essa pergunta, Bernoulli afirmou:

Se designarmos o número de casos tendendo a infinito por $N$, em $N / 2$ casos, Paulo ganha um real, em $N / 4$ casos ele ganha dois reais, em $N / 8$ ele ganha quatro, em $N / 16$ ele ganha oito, e assim por diante, ad infinitum. Se representarmos a fortuna inicial de Paulo por $\alpha$, usando a proposição (apresentada em 2.6), o ganho esperado valerá:

$$
(\alpha+1)^{1 / 2} \cdot(\alpha+2)^{1 / 4} \cdot(\alpha+4)^{1 / 8}-\alpha
$$

dessa fórmula concluímos que tal valor deverá ser tão maior, quanto maior for a fortuna inicial de Paulo e nunca atingirá infinito a menos que a fortuna inicial seja infinita. Adicionalmente, podemos obter o seguinte corolário. Se Paulo possuísse absolutamente nada antes do início do jogo, a sua expectativa de ganho seria:

$$
1^{1 / 2} \cdot 2^{1 / 4} \cdot 4^{1 / 8} \cdot 8^{1 / 16} \cdots=2
$$

Se ele possuísse inicialmente dez reais, sua oportunidade de ganho valeria aproximamente três reais; quatro reais, se sua fortuna fosse de cem reais e seis, se possuísse mil. Podemos facilmente inferir a partir disso quão imensa deveria ser a fortuna de um homem para que faça sentido pagar vinte reais pela oportunidade de Paulo. 
Sendo o jogo que caracteriza o paradoxo de São Petersburgo infinito, claramente cabe a crítica ${ }^{5}$ que evidentemente não se pode designar um número real $N$ como infinito o que torna uma aplicação direta do resultado obtido em (2.5) inviável. Contudo, colocando-se em termos de probabilidade como feito em (2.6), e novamente considerando que o indivíduo não possui sequer um real inicialmente, tem-se:

$$
\begin{aligned}
& \hat{x}=\left(x_{1}\right)^{p_{1}} \cdot\left(x_{2}\right)^{p_{2}} \cdots \\
& \hat{x}=1^{1 / 2} \cdot 2^{1 / 4} \cdot 4^{1 / 8} \cdot 8^{1 / 16} \cdot 16^{1 / 32} \cdot 32^{1 / 64} \ldots \\
& \hat{x}=2^{1 / 4} \cdot 2^{2 / 8} \cdot 2^{3 / 16} \cdot 2^{4 / 32} \cdot 2^{5 / 64} \ldots \\
& \hat{x}=2^{\sum_{i=1}^{\infty} \frac{i}{2^{i+1}}} \\
& \hat{x}=2
\end{aligned}
$$

Por fim, duas outras aplicações interessantes são sugeridas por Bernoulli para sua função de utilidade esperada.

A primeira comprova empiricamente um conceito geralmente observado na prática de que para alguns indivíduos é razoável arriscar-se em negócios duvidosos, enquanto para outros, isso seria uma tolice:

Suponha um mercador de Petersburgo chamado Caio, que compra commodities em Amsterdã que podem ser vendidas em Petersburgo por dez mil reais. Uma vez encomendadas, as mercadorias são embarcada em um navio e Caio está em dúvida se contrata um seguro para esse transporte. Ele sabe que nessa época do ano, em viagens de Amsterdã a Petersburgo, cinco em cada cem navios geralmante são perdidos. No entanto, não há seguro disponível por valor menor do que oitocentos reais por carregamento,

\footnotetext{
${ }^{5}$ Embora Bernoulli tenha publicado seu trabalho na revista da Academia Imperial de Ciências de São Petersburgo de 1738 em latim, é a versão que aparece na revista Econometrica Vol. 22 de 1954, do Dr. Louise Sommer, da American University, que realizou o primeiro trabalho de tradução para o inglês que costuma ser a referência da maioria dos trabalhos mais novos. Sommer foi auxiliado pelo Prof. Karl Menger, do Illinois Institute of Tecnology. Esse último teria sido o primeiro matemático a criticar o tratamento que Bernoulli deu às quantidades infinitas.
} 
uma quantia considerada abusiva. A questão é, portanto, qual a fortuna que Caio deve possuir, além dos bens que estão sendo levados em consideração, de forma a fazer uma sensível diferença para ele caso se abstenha de contratar o seguro? Se $x$ representa a sua fortuna inicial, então, o valor esperado da sua fortuna final ponderando os casos que a mercadoria chegue com segurança ou não, é dado por $\sqrt[100]{(x+10.000)^{95} x^{5}}=\sqrt[20]{(x+10.000)^{19} x}$, se ele se abstiver de assegurar o transporte. Com o seguro, ele deve ter uma fortuna certa de $x+9.200$. Igualando essas duas magnitudes obtemos: $(x+10.000)^{19} x=(x+9.200)^{20}$ ou, aproximadamente, $x=5.043$. Se, portanto, Caio possui, fora o recebimento da mercadoria, uma quantia maior do que 5.043 reais, ele estará tomando uma decisão correta ao não contratar o seguro. Caso contrário, se sua fortuna for menor do que essa quantia, ele deve contratar o seguro. E se nos perguntarem "qual deve ser a fortuna mínima possuída pelo homem que oferece o seguro de forma que sua decisão possa ser considerada racional?". Devemos responder, seja $y$ sua fortuna,

$$
\sqrt[20]{(y+800)^{19} \cdot(y-9.200)}=y
$$

ou aproximadamente, $y=14.243$, o que é um resultado previsível empregando-se a lógica a seguir, sem a necessidade de cálculos adicionais: Um homem com menor fortuna seria tolo em prover esse tipo de certeza a um terceiro, mas faz sentido para um homem mais rico provê-la. É daí que fica claro porque tal tipo de seguro é tão útil uma vez que apresenta vantagens a todas as pessoas envolvidas.

A segunda aplicação que seria fruto da utilidade esperada de Bernoulli é que, em certa medida, pode ser aconselhável dividir os bens embarcados sujeitos a algum risco em várias pequenas porções, do que expô-los todos de uma vez. Novamente apresenta-se o exemplo sugerido pelo matemático: 
Semprônio possui em sua casa bens no valor total de 4.000 reais. Adicionalmente, possui 8.000 reais em commodities no exterior que precisariam ser transportadas por navio. Todavia, a experiência mostra que 1 em cada 10 navios naufragam no percurso. Caso Semprônio confie todos as mercadorias a uma única embarcação a utilidade esperada das mesmas será de 6.751 reais, pois,

$$
\sqrt[10]{12.000^{9} \cdot 4.000^{1}}-4.000
$$

Se, no entanto, dividir o valor das mercadorias igualmente entre dois navios o valor esperado passa a

$$
\sqrt[100]{12.000^{81} \cdot 8.000^{18} \cdot 4.000^{1}}-4.000 \text {, ou seja, } 7.033 \text { reais }
$$

Dessa maneira o valor esperado das mercadorias de Semprônio crescerá quanto menor for a proporção confiada a cada navio. Contudo, essa esperança matemática não deverá nunca ser superior a 7.200 reais. Esse conselho será igualmente útil para aqueles que investem em notas de câmbio e outros empreendimentos de risco. 


\subsection{A solução de Cramer}

De Bernoulli[1] também soube-se que o matemático Gabriel Cramer ${ }^{6}$ havia se interessado e dado sua solução ao paradoxo ${ }^{7}$.

Cramer[5], tal como Bernoulli faria dez anos mais tarde, inicia a sua solução baseando-se no conceito da utilidade do dinheiro:

(...). O que se busca é uma explicação para a discrepância entre o cálculo matemático do valor de entrada do jogo (cuja a soma tende ao infinito) e a avaliação vulgar (em que nenhuma pessoa razoável estaria disposta a pagar mais do que vinte reais para jogar). Eu acredito que ela é resultado do fato de que, em teoria, os matemáticos avaliam o dinheiro em proporção à sua quantidade em quanto que, na prática, as pessoas de bom senso avaliam-no em proporção à utilidade que pode ser obtida dele. A esperança matemática infinita surge das enormes fortunas que são possíveis de se ganhar caso a cara apenas apareça no centésimo, ou talvez no milésimo lançamento. Agora, se pensarmos racionalmente como um homem comum faria, essa soma vale não mais para mim, traz-me não mais prazer, influencia-me não mais, do que uma quantia de dez ou vinte milhões de reais ${ }^{8}$. Suponhamos, portanto, que qualquer quantia acima de 10 milhões de reais, ou (para simplificar) acima de $2^{24}=166.777 .216$ de reais, equivaleria para ele de fato a no máximo $2^{24} \mathrm{ou}$, melhor do que isso, não importando quantas vezes a moeda fosse lançada até finalmente

\footnotetext{
${ }^{6}$ Nascido em Genebra, Suíça (1704-1752), mais conhecido pelo seu teorema em álgebra linear a "Regra de Cramer".

${ }^{7}$ Da mesma forma que Daniel Bernoulli, Cramer havia tomado contato com o problema através da carta de Nicolas de Bernoulli de 1713. Contudo, sua resposta teria sido enviada a Nicolas em 1928.

${ }^{8}$ Lembrando que essa quantia de fato é mencionada em ducados e, talvez pudesse equivaler a bilhões de reais.
} 
aparecer a coroa. Nesse caso a minha esperança matemática seria

$$
\begin{aligned}
& E(U)=\frac{1}{2} \cdot 1+\frac{1}{4} \cdot 2+\frac{1}{8} \cdot 4+\cdots+\frac{1}{2^{25}} \cdot 2^{24}+\frac{1}{2^{26}} \cdot 2^{24}+\cdots \\
& E(U)=\underbrace{\frac{1}{2}+\frac{1}{2}+\frac{1}{2}+\cdots}_{24 \text { vezes }}+\frac{1}{2}+\frac{1}{4}+\frac{1}{8}+\cdots \\
& E(U)=12+1 \\
& E(U)=13
\end{aligned}
$$

Bernoulli[1] achou tal teoria vaga e sujeita a contra-argumentos. Por que seria $2^{24}$ reais um número especial? Se para o sujeito em questão o ganho marginal em utilidade acima $2^{24}$ reais é nulo, então, valores acima do mesmo não deveriam ser considerados no cálculo da utilidade esperada e a mesma seria, dessa forma, doze reais e não 13.

Alternativamente, uma base argumentativa, também exposta por Cramer, e mais convincente para Bernoulli, é aquela em que se assume alguma função utilidade que resolve a característica explosiva do ganho exponencial do jogo.

Cramer finalmente compactua que 100 milhões de reais de fato apresentam uma maior utilidade do que 10 milhões de reais, mas essa utilidade não seria dez vezes maior. Se, por exemplo, assumir-se que o valor "moral" dos bens como diretamente proporcional à raiz quadrada de sua quantidade a esperança ficaria:

$$
\begin{aligned}
& E(U)=1 / 2 \sqrt{1}+1 / 4 \sqrt{2}+1 / 8 \sqrt{4}+1 / 16 \sqrt{8}+\cdots \\
& E(U)=\frac{1}{2-\sqrt{2}} \approx 1,71
\end{aligned}
$$

um valor mais próximo do que chegou Bernoulli[1], como mostrou-se em (2.9). 


\subsection{Soluções discutidas por Karl Menger}

Segundo consta na literatura especializada ${ }^{9}$ poucas contribuições significativas à questão do paradoxo teriam sido feitas no sentido de propor novas soluções ou mesmo criticar as existentes até a primeira metade do século XX. Foi apenas em 1934 que algo realmente inovador apareceu nos escritos de Karl Menger ${ }^{10}$ quando da publicação de seu artigo intitulado "O Papel da Incerteza Economia", Menger[13], em que são apresentadas novas e surpreendentes considerações acerca do paradoxo de São Petersburgo.

Após definir formalmente o problema na primeira seção do referido trabalho, o matemático seguiu nas seções posteriores criticando o que havia sido concebido tão naturalmente por Bernoulli e outros. Iniciou com uma crítica ao uso da palavra "paradoxo".

De fato não havia para ele nenhum problema teórico no fato de uma pessoa avaliar a esperança matemática de um determinado jogo como infinita e, ainda que haja discrepância entre os lucros de fato auferidos em algumas observações do jogo e o valor obtido por uma fórmula previamente definida, não havia caracterização de um paradoxo do ponto de vista lógico.

\subsubsection{A alegação de inconsistência}

É natural que tal discrepância tenha despertado a curiosidade de muitas pessoas e não só a dos matemáticos. É nessa discrepância que estaria a alma do problema para Menger e não no caráter técnico da esperança infinita.

Sendo o problema relacionado com o comportamento econômico de pessoas

\footnotetext{
${ }^{9}$ Tal como constatado por Samuelson[14].

${ }^{10}$ Karl Menger(1902-1985), filho do economista Carl Menger(1840-1921). Esse último foi fundador da Escola Austríaca de Economia, famoso por contribuir com o desenvolvimento da Teoria Utilitarista, que em suma, advoga que os preços de bens e serviços são formados a partir da utilidade marginal, isto é o acréscimo de utilidade ao comprador pela última aquisição de determinado bem. Ao definir dessa maneira a formação de preço, Carl refuta a teoria de economistas clássicos com Adam Smith e Davi Ricardo que atribuiam à formação de preços o custo de produção.
} 
normais, é possível que se espere que a solução exista no campo da psicologia econômica. Nesse sentido sempre poder-se-ia alegar a incosistência do jogo com base em argumentos do tipo:

- As regras do jogo permitem ganhos extremamente altos que impossibilitam ao jogador que oferece o jogo honrar sua aposta, uma vez que o mesmo possui uma fortuna finita. O que é suficiente para considerar-se a esperança infinita como ilusória;

- Cada vez que a moeda é lançada, certo tempo é dispendido. Isso implica que em algum momento o jogo deverá ser interrompido mesmo que a cara ainda não tenha aparecido.

Contudo, para Menger[13], esse tipo de argumentação não fazia parte do enunciado do problema e, portanto, não deveria ser considerada.

\subsubsection{Solução com base no conceito frequentista de probabilidade}

Outra possivel solução para a questão da discrepância é a seguinte: apenas se for possível repetir inúmeras vezes um jogo de azar é que se torna razoável arriscar, em cada jogo, o valor esperado.

Aplicado a uma única rodada, o conceito de esperança matemática perderia o seu sentido prático. Para Menger[13] essa realidade era especialmente verdadeira para o paradoxo de São Petersburgo. O real significado da afirmação de que o jogador que compra o direito de jogar tem esperança matemática infinita é, de acordo com essa perspectiva, que não importa quão alto seja o preço cobrado para se jogar, sempre haverá uma vantagem para o jogador comprador, desde que o jogo seja praticado com frequência suficiente e o jogador comprador aposte a mesma quantia todas as vezes em cada jogo.

A conclusão de Menger é que esse argumento não constitui uma solução ao problema visto que não responde a questão básica da discrepância existente entre quanto as pessoas estão dispostas a pagar pelo jogo e se isso é maior 
ou muito menor do que a esperança matemática calculada. De fato, essa afirmação somente ressalta a particularidade do problema.

\subsubsection{Soluções baseadas em funções-utilidade sem li- mites}

É por ter criticado esse tipo de solução que o artigo de Karl Menger[13], com relação ao paradoxo de São Petersburgo, é mais conhecido e citado. A própria solução de Daniel Bernoulli[1] está contida nesse grupo de soluções.

Como apresentado anteriormente na solução que Bernoulli[1] propôs, no artigo que melhor introduziu o problema à comunidade científica, inauguravase o importante conceito de avaliação subjetiva da riqueza, que utilizava como instrumento uma função utilidade.

Mais precisamente a função utilidade usada para avaliar a riqueza obtida através de um jogo não era quantificada em absoluto, isto é, diretamente medida somente pelo ganho no jogo. Ela levava em consideração a fortuna que o jogador possuía anteriormente, sendo os ganhos vistos como parcelas adicionais à fortuna pré-existente. A função utilidade deveria ser diretamente proporcional aos ganhos adicionais, porém, inversamente proporcional à riqueza pré-existente.

No que tangia o conceito de função utilidade, Menger não deixou de ressaltar que considerava uma "excelente" idéia quantificar a riqueza não somente pelo seu tamanho mas também pela fortuna do avaliador, citando inclusive seu papel no desenvolvimento da Teoria Econômica ${ }^{11}$. Contudo, para ele, tomar esses mecanismos para resolver o paradoxo significava apresentar uma solução ad hoc, que falha em explicar o problema em seu âmago.

Mesmo evitando-se a discussão se realmente a função logarítmica, que

\footnotetext{
${ }^{11}$ Esse comentário feito por Karl Menger com toda certeza buscava fazer justiça aos escritos de seu pai, Carl Menger, um proeminente economista considerado o fundador da Escola Austríaca, famosa por contribuir com o desenvolvimento da Teoria da Utilidade Marginal.
} 
apresenta as características "desejáveis" descritas acima, realmente é a que melhor representa o comportamento de indivíduos normais ao avaliar a riqueza, a mesma poderia ser formalmente excluída como uma solução definitiva ao paradoxo, bastando para isso, uma pequena alteração no sistema de premiação.

Originalmente, Menger propôs um contra-exemplo trivial em que, ao invés de se premiar com $2^{n-1}$ reais caso a face cara venha aparecer apenas no nésimo lançamento pagar-se, por exemplo, $\alpha \cdot e^{2^{n}}-\alpha$ (em que $\alpha$ é a fortuna inicial do jogador) se a cara ocorrer no n-ésimo lançamento. Dessa maneira, mesmo com a implementação da função subjetiva logarítmica de Bernoulli, a esperança dessa nova função volta a ser infinita. Retomando a fórmula da função utilidade esperada ${ }^{12}$ :

$$
\begin{aligned}
& E(U)=p_{1} \cdot b \cdot \log \left(1+\frac{x_{1}}{\alpha}\right)+\cdots+p_{n} \cdot b \cdot \log \left(1+\frac{x_{n}}{\alpha}\right) \\
& E(U)=\frac{1}{2} \cdot b \cdot \log \left(1+\frac{x_{1}}{\alpha}\right)+\cdots+\frac{1}{2^{n}} \cdot b \cdot \log \left(1+\frac{x_{n}}{\alpha}\right)
\end{aligned}
$$

Aplicando-se o sistema de premiação proposta por Menger:

$$
\begin{aligned}
& E(U)=\frac{1}{2} \cdot b \cdot \log \left(1+\frac{\alpha \cdot e^{2}-\alpha}{\alpha}\right)+\cdots+\frac{1}{2^{n}} \cdot b \cdot \log \left(1+\frac{\alpha \cdot e^{2^{n}}-\alpha}{\alpha}\right) \\
& E(U)=\frac{1}{2} \cdot b \cdot \log \left(1+e^{2}-1\right)+\cdots+\frac{1}{2} \cdot b \cdot \log \left(1+e^{2}-1\right) \\
& E(U)=b+\cdots+b, \text { em que } b>0 \text { é uma constante arbitrária. } \\
& E(U)=\infty
\end{aligned}
$$

Teorema 1 (Geral por Karl Menger) Ao avaliar riquezas adicionais à uma fortuna existente através de uma função utilidade sem limite sempre existe um jogo do tipo Petersburgo em que a função subjetiva esperada do agente tomador do risco será infinita.

\footnotetext{
${ }^{12} \mathrm{~A}$ fórmula original para função utilidade proposta por Bernoulli era $u=b \cdot \log \left(\frac{x}{\alpha}\right)$ (sendo $u$ a utilidade, $x$ a fortuna, $b$ e $\alpha$ constantes arbitrárias). Contudo, Menger a reconstruiu com uma ligeira diferença $u=b \cdot \log \left(1+\frac{x}{\alpha}\right)$ que facilita a demonstração de seu ponto de vista e preserva a característica logarítmica da curva.
} 
Prova Da hipótese de que a função subjetiva é ilimitada pode-se assumir que existe uma adição à fortuna $D_{1}$ em que o valor subjetivo $u\left(D_{1}\right)$ é de pelo menos $2^{0}=1$ real. Existe igualmente uma adição $D_{2}$ cujo valor subjetivo será avaliado em, pelo menos, $2^{1}=2$ reais. Genericamente, para cada número natural $n$ existe uma adição $D_{n}$ tal que o valor subjetivo será de pelo menos $2^{n-1}$ reais. Sendo a esperança subjetiva dada por:

$$
E(U)=\frac{1}{2} u\left(D_{1}\right)+\frac{1}{4} u\left(D_{2}\right)+\frac{1}{8} u\left(D_{3}\right)+\cdots
$$

A mesma será pelo menos igual a

$$
E(U)=\frac{1}{2} \cdot 1+\frac{1}{4} \cdot 2+\frac{1}{8} \cdot 4+\cdots, \text { portanto infinita. }
$$

\subsubsection{Soluções baseadas em funções-utilidade limita- das}

A idéia de se avaliar um jogo de apostas não pelo valor absoluto dos possíveis ganhos, mas sim por uma função subjetiva aplicada a esses valores, torna viável ao avaliador determinar um nível de fortuna $W^{*}$ tão elevado tal que, para qualquer prêmio $W$, o valor $u(W)$ será inferior a $W^{*}$. Nesse contexto, forçosamente tem-se que a esperança subjetiva será finita e menor do que:

$$
\frac{W^{*}}{2}+\frac{W^{*}}{4}+\frac{W^{*}}{8}+\frac{W^{*}}{2^{n}}+\cdots, \text { que é exatamente igual a } W^{*}
$$

Um argumento recorrente que corrobora com uso de funções-utilidade limitadas é que existe uma quantidade finita de dinheiro, ou coisas que o dinheiro pode comprar no mundo.

Richard Jeffrey ${ }^{13}$, anos após e à revelia da publicação de Menger[13], continuava a defender esse argumento da finitude da utilidade. Isso fica claro no

\footnotetext{
${ }^{13}$ Richard C. Jeffrey (1926-2002) foi um filósofo americano especialista em lógica e probalista. Estudioso e ilustre contribuidor da Teoria da Decisão, Jeffrey era um fervoroso defensor da abordagem bayesiana em probabilidade.
} 
texto abaixo extraído de Jeffrey(1983):

Put briefly and crudely, our rebuttal of the St. Petersburg paradox consists in the remark that anyone who offers to let the agent play the St. Petersburg game is a liar, for he is pretending to have an indefinitely large bank.

A discordância principal de Menger com esse tipo de argumento é novamente o fato dele não atacar o problema de maneira legítima. Para ele o problema principal continua residindo, não no fato de os ganhos mais elevados terem valores subjetivos que crescem com taxas cada vez menores (e, nesse caso, limitados), e sim no problema de que eles têm probabilidades tão ínfimas que na prática não são consideradas factíveis pelo agente comprador da aposta.

Esse ponto de vista é melhor expressado por Menger com um novo exemplo. Tome-se um novo jogo do tipo São Petersburgo em que se a primeira cara sair no n-ésimo lançamento, o prêmio a ser pago também será de $2^{n-1}$. Contudo, se a cara não aparecer até o k-ésimo lançamento, o jogo é encerrado e o jogador recebe $2^{k-1}$. Esse jogo está condenado a ser finito por definição e sua esperança matemática (sem o uso de função utilidade) é:

$$
\begin{aligned}
E(U) & =\frac{1}{2} \cdot 1+\frac{1}{4} \cdot 2+\cdots+\frac{1}{2^{n}} \cdot 2^{n-1}+\cdots+ \\
& +\frac{1}{2^{k-1}} \cdot 2^{k-2}+\frac{1}{2^{k}} \cdot 2^{k-1}
\end{aligned}
$$

É fácil ${ }^{14}$ ver que, nesse caso:

$$
E(U)=\frac{k}{2}
$$

Logo, quanto maior $k$, maior a esperança matemática calculada pelo apostador. Entretanto, à medida que $k$ cresce, não há nenhuma alteração na expectativa do apostador no que se refere a quantas vezes ele vai "conseguir"

\footnotetext{
${ }^{14}$ Todos as parcelas da esperança valem $1 / 2$, como tem-se $k$ parcelas, segue o resultado. Em Menger[13] esse resultado aparece errado, valendo $\frac{k+1}{2}$.
} 
manter a face cara sem aparecer e com isso continuar no jogo. Parece haver certo número de lançamentos que representam uma barreira praticamente intransponível. Mesmo assim aumentando-se $k$ a esperança aumenta sem limites.

Esse jogo proposto ilustra muito claramente que quanto maior $k$, maior será a discrepância entre a avaliação obtida pela esperança matemática e o comportamento real de um apostador, o dito bom senso. Quando $k$ vai ao infinito, tem-se o caso trivial do paradoxo.

\subsubsection{O comportamento do apostador}

Para Menger a explicação do paradoxo está no comportamento do apostador. Como cada pessoa avalia a proposta de ganhar a quantia $D$ com probabilidade $p$, um tipo de "pacote" $(p, D)$.

Essa avaliação não é algo que possa ser feito com uma única pergunta. Um questionamento possível seria "qual a maior quantia que um indivíduo estaria disposto a pagar por $(p, D)$ ?", mas também a pergunta poderia ser "qual quantia a ser recebida com certeza que é equivalente a $(p, D)$ ?".

A primeira pergunta seria mais adequada quando um determinado apostador se propõe a comprar um determinado jogo. Já a segunda pergunta é ligeiramente diferente, sendo mais apropriada a uma situação em que o apostador pode escolher entre uma soma em dinheiro a ser recebida com certeza ou o pacote $(p, D)$. Menger afirma que, de maneira geral, a primeira pergunta costuma ser respondida com um valor relativamente menor do que a segunda.

Menger acreditava que para as perguntas mais frequentes, as quais diariamente impõem-se aos indivíduos, a primeira (entre as duas perguntas mencionadas) seria a mais adequada ao objeto de estudo. Ao assumir que a compra de um pacote $(p, D)$ realmente deve ser avaliada com base em leis subjetivas, isto implicaria, por exemplo que quando as possibilidades (de ganho) são altíssimas, o indivíduo não estaria disposto a arriscar-se. Embora 
essa afirmação pareça peculiar à primeira vista, um olhar mais atento mostra que isso pode ser confirmado experimentalmente, tal como fez o próprio Bernoulli. Parece bastante improvável que alguém arriscaria uma porção considerável de sua fortuna, digamos $W^{\prime}$, em um jogo que pague com probabilidade $p=99 / 100$ o prêmio $D=(100 / 99) W^{\prime}$ (equivalente a quase $1,01 W^{\prime}$ ), muito embora esse jogo proposto tenha valor esperado $W^{\prime}$. De fato poucos jogadores apostariam $W^{\prime}$, mesmo com $99 \%$ de probabilidade de ganhar $1,1 W^{\prime}$ ou $1,2 W^{\prime}$.

Para Menger essa constatação não implica que um empresário tenha uma preferência por negócios relativamente mais arriscados àqueles quase certos. Se por um lado os jogos estudados somente oferecem duas possibilidades: ganhar ou perder, por outro, as circunstâncias que geralmente cercam os homens de negócios são tais que, mesmo que eles não "ganhem", é possível conseguir boa parte de seu investimento de volta. Quanto maior for a parte de investimento original que ele consiga certamente recuperar, maior será sua predisposição a negócios com maiores probabilidades de ganho. Nesse contexto, da teoria de jogos que envolvem probabilidades, só será considerado sob risco o capital que não puder ser recuperado com certeza. Todavia, se o empresário depara-se com negócios em que, caso ele não seja "ganhador", há perda substancial de seu patrimônio, sua avaliação do preço do jogo será em conformidade com o comportamento típico do apostador, atribuindo pouco valor mesmo às transações com grandes possibilidades de ganho. Nesse caso, maior será a discrepância entre o valor que o homem de negócios está disposto a pagar e o valor esperado do jogo.

À semelhança do que fez Bernoulli[1], Menger fez uma pequena modelagem do comportamento do apostador.

Iniciou definindo como $w$ a parte da fortuna que um indivíduo estaria disposto a arriscar em jogos de azar. Salientou que, apesar de haver diferenças de um indivíduo para outro, em circunstâncias normais o valor de $w$ estaria muito mais próximo de 0 do que de 1 .

Existem casos extremos, todavia, em que $w=1$, isto é, casos em que os 
indivíduos estariam dispostos a apostar toda a sua fortuna em determinado jogo que apresentasse ganhos elevados. Menger apresentou dois exemplos hipotéticos para ilustrar esses casos: o primeiro é de um indivíduo que tem a necessidade de um tratamento médico o qual pode custar muitas vezes o valor de sua casa própria (e de todos os seus outros bens) e que, não tendo outra fonte de recursos, resta-lhe apenas a opção de arriscar todo o seu capital em determinado jogo capaz de premiá-lo com o dinheiro do tratamento. O segundo exemplo citado é de um indivíduo que possui a necessidade de pagar uma dívida de honra, em que viver sob tais circunstâncias pode parecer ao devedor que não vale a pena, e, não tendo recursos suficientes para liquidála, prefere arriscar-se num jogo que pode ter como prêmio um valor igual ou superior à dívida.

Adicionalmente, em seu modelo, Menger supôs existir uma fortuna mínima $U$ com a qual o indivíduo concordaria em continuar seguindo com sua vida e que, se sua fortuna $W$ for consideravelmente menor do que $U$, provavelmente para esse indivíduo $w=1$. Normalmente, $W$ é maior do que $U$. Alguns podem considerar $U$ como zero, porque buscarão continuar vivendo independentemente de possuir alguma fortuna.

Porém, poder-se-ia considerar alternativamente um nível de fortuna $U^{\prime}$ que representasse o necessário para o indivíduo continuar seu padrão atual de consumo, e $Z$ um nível de fortuna almejado. Se $W$ está entre $U^{\prime}$ e $Z$, então esse homem, muito provavelmente, apenas arriscaria quantias inferiores a $W-U^{\prime}$. Ademais, quanto menor for a chance de homem obter a diferença desejada, $W-U^{\prime}$, através de seu trabalho e poupança, mais a razão $w$ se aproximará de seu máximo $\frac{W-U^{\prime}}{W}$. Ao mesmo tempo, o homem buscará empreendimentos em que a possibilidade de ganho seja próxima à diferença $Z-W$.

Outro aspecto do comportamento individual a ser analisado ao se ponderar a compra de $(p, D)$ é a probabilidade $p$. A primeira regra básica, tal como observou Cramer[5], é que as pessoas tendem a subvalorizar jogos com baixíssimas probabilidades de ganho. Um indivíduo $H$ associará uma probabilidade mínima que ele estaria disposto a arriscar a quantia $R$, isto é, $p_{H}(R)$. 
É evidente que nessas circunstâncias $H$ só aceitaria participar de jogos em que $p \cdot D$ seja maior do que $\mathrm{R}$, porém, quanto menor for a diferença $p_{H}-p$, isto é, quanto menor a diferença entre a probabilidade mínima aceita pelo indivíduo para arriscar $R$ e a probabilidade oferecida no jogo, menor será a avaliação do preço do jogo dada por $H$.

Nessa modelagem, a tendência é que os jogos com probabilidades muito baixas (isto é próximas de 0) ou muito altas (próximas de 1) tendem a ser subvalorizados pelos indivíduos. Portanto, seria justamente nos jogos com probabilidades medianas que o valor subjetivo atribuído pelo apostador tende a ser mais próximo da esperança matemática. Em alguns casos os jogos de probabilidade mediana são até mesmo supervalorizados. A confirmar essa conclusão estão as loterias, roletas e jogos similares, em que o jogador paga, com prazer e muitas vezes com conhecimento de causa, um valor superior à esperança matemática para participar. É essa diferença responsável pelas despesas e lucros dos organizadores de loterias e donos de cassinos.

A probabilidade em que a supervalorização do preço do jogo concretiza-se dependeria, segundo Menger, de diversos fatores como: $U^{\prime}, Z$ e outros de foro pessoal do jogador. 


\section{Capítulo 3}

\section{Aplicações do paradoxo}

O conceito de função utilidade que, conforme apresentado anteriormente, constitui um desdobramento direto da tentativa de Bernoulli em resolver o paradoxo, desenvolveu-se e contribuiu com a Teoria Microeconômica notadamente pela sua capacidade de modelar matematicamente o comportamento individual. Fez com que não só quantias em dinheiro passassem a ser avaliadas pelas funções utilidades subjetivas, mas de maneira geral todos os bens produzidos pela sociedade.

Contudo, a importante contribuição mencionada (no parágrafo anterior) surgiu mais como uma ferramenta para solucionar São Petersburgo do que propriamente algo que envolva diretamente o conceito do jogo. Nesse sentido, provavelmente a aplicação mais direta conhecida é devida a Durand[7].

Durand estava particularmente preocupado com o processo de formação de preços no mercado acionário americano em meados da década de 1950. Conhecedor das teorias de valuation ${ }^{1}$ existentes até sua época, encontrou exatamente na dinâmica do paradoxo uma crítica contundente às mesmas.

\footnotetext{
${ }^{1}$ Valuation é um termo do inglês amplamente empregado para designar o processo de apuração do valor de mercado de determinada empresa ou de qualquer empreendimento. Ela é aplicada em diversos contextos como análise de investimentos, revisões orçamentárias, fusões e aquisições, relatórios contábeis e pode servir como base para aplicação de impostos e litígios.
} 


\subsection{Principal conceito de valuation}

Talvez o conceito mais primordial ${ }^{2}$ de todo processo de valuation (e uma espécie de axioma no mundo das finanças) é que um determinado ativo (ou passivo) deve ter seu valor presente $V P$ medido pelos seus fluxos de caixa $F C_{k}$ 's futuros esperados que deverão ser descontados a uma determinada taxa $i$. Usando o conceito de juros compostos:

$$
V P=\frac{F C_{1}}{(1+i)^{1}}+\frac{F C_{2}}{(1+i)^{2}}+\frac{F C_{3}}{(1+i)^{3}}+\cdots
$$

Tome-se, por exemplo, um empresário do setor do vestuário que deseja adquirir uma máquina que deverá aumentar a produtividade de sua fábrica.

Suponha-se que tal máquina possua uma vida útil de 7 anos e que seja capaz de aumentar a produção em 50.000 pares de meia por ano. Se esse volume de produção aumentar o lucro líquido em 50 mil reais (considerando que a aquisição da máquina não demandará gastos adicionais com mão-deobra e instalação e já descontados os custos anuais adicionais de matériaprima, manutenção e energia dispendidos por ela), o valor presente (isto é para aquisição imediata) e justo desse maquinário dependerá apenas da determinação de uma taxa de desconto para ser definido, aplicando (3.1). A taxa de desconto geralmente empregada é aquela que, dado o risco ${ }^{3}$ do empreendimento, o comprador consideraria justa como taxa de remuneração pelo seu capital investido. Diga-se portanto que $i=30 \%$ :

$$
\begin{aligned}
V P & =\frac{50.000}{(1+0,3)^{1}}+\frac{50.000}{(1+0,3)^{2}}+\frac{50.000}{(1+0,3)^{3}}+\cdots+\frac{50.000}{(1+0,3)^{7}} \\
V P & \approx 140.105,61
\end{aligned}
$$

\footnotetext{
${ }^{2}$ Para outros importantes conceitos de valuation recomenda-se a leitura de CopelandKoller-Murrin[4].

${ }^{3}$ Lembrando que existem inúmeros fatores de risco que podem comprometer a produção em uma fábrica de meias. Pode haver uma inundação no galpão, ou o custo de outros fatores de produção podem sufocar os lucros, a abertura à importação de meias da China pode derrubar o preço de mercado etc.
} 
Logo o valor aproximado dessa máquina segundo os fundamentos de valuation é de aproximadamente 140 mil reais.

Da mesma forma como o empresário acima pôde calcular o valor de um bem de capital a ser adquirido, um investidor pode estimar o valor de uma empresa. E sendo essa empresa de capital aberto, isto é, com ações negociadas em bolsa de valores, grosso modo bastaria dividir o valor da empresa encontrado dessa forma pelo número de ações existentes para se ter um valor fundamental para o preço daquela determinada ação.

No caso da avaliação do valor de uma empresa, os fluxos futuros poderão ser estimados de formas diferentes. Podem ser previstos, por exemplo, pelas expectativas de receitas estimadas pela área de vendas, ou de outras fontes de receitas, podem ser contratos de fornecimentos já celebrados por período determinado e que geralmente afetam o caixa mensalmente, podem ser custos com mão-de-obra, investimentos, pagamentos e recebimentos de empréstimos de curto e longo prazo etc. Quanto mais informação se tenha sobre os expedientes da empresa, maior será a previsibilidade de seus fluxos futuros esperados.

Por esses motivos, não é de se estranhar que os investidores mais ávidos por oportunidades de apreciação estejam sempre em busca de ações de empresas que, além de distribuir dividendos (oriundos da distribuição de lucros), apresentem grandes chances de crescimento. Como o valor dos ativos da empresa já existentes e conhecidos supostamente já estão incorporados no valor presente da ação, o investidor têm na expectativa de dividendos sua base de formação dos fluxos futuros a serem descontados para a estimação do valor justo da ação e o crescimento das empresas deve também manifestar-se no crescimento dos dividendos.

\subsection{Fluxos de caixa e o paradoxo}

O ponto de partida de Durand é justamente as dificuldades que se impõe para o desconto de todos esses fluxos futuros na tentativa de encontrar o preço da 
ação. A primeira dificuldade, principalmente do ponto de vista prático, seria justamente a determinação de métodos eficientes de estimação de vendas, receitas, despesas e dividendos. A segunda, mais teórica, seria determinar a que taxa deve-se descontar tais fluxos. Alguns autores ${ }^{4}$ até mesmo anteriores a Durand já sugeriam que as taxas de desconto utilizadas não deveriam ser uniformes, devendo variar de pagamento em pagamento.

O trabalho de Clendemin-Cleave[3] serviu de alerta a Durand especialmente para o fato que descontar perpetuidades a taxas constantes pode levar o preço de ações a valores infinitos. Evidentemente a semelhança entre o mecanismo de desconto e a infinitude irracional chamaram a atenção dos dois autores para o paradoxo de São Petersburgo e Durand[7] comprometeu-se a estudar meticulosamente essa relação.

As modificações propostas são as seguintes. A probabilidade de observarse a face cara, ao invés de $1 / 2$, passa a ser $1 /(1+i)$. A taxa de crescimento da premiação, em substituição ao valor 2 , passa a ser $(1+g)$. Uma modificação mais extensa, e que justamente é a de maior interesse, sugere uma série de pagamentos crescentes. Com efeito, Pedro concorda pagar $D$ reais se a face cara aparecer no primeiro lançamento, $D(1+g)$, se ela aparecer no segundo; $D(1+g)^{2}$ se ela aparecer no terceiro e assim sucessivamente até a cara finalmente surgir. Logo a esperança matemática da modificação fica:

$$
\frac{D}{1+i}+\frac{D(1+g)}{(1+i)^{2}}+\frac{D(1+g)^{2}}{(1+i)^{3}}+\cdots+\frac{D(1+g)^{(n-1)}}{(1+i)^{n}}
$$

Essa série é aritmeticamente equivalente à série de descontos de pagamentos de dividendos, iniciando com um dividendo de $D$ reais, crescendo em cada período a uma taxa $g$ e descontado à taxa $i$. É possível resumir a esperança acima (3.2) da seguinte forma:

$$
D \frac{1-(1+g)^{n} /(1+i)^{n}}{i-g}
$$

\footnotetext{
${ }^{4}$ Como apresentado em Williams[16].
} 
Se o número $n$ de termos de (3.3) for levado ao infinito, expressando nesse caso uma hipótese de perpeituidade e, ainda, no caso da taxa de desconto $i$ ser maior do que a taxa de crescimento do dividendo, tem-se:

$$
\begin{aligned}
\lim _{n \rightarrow \infty} D \frac{1-\frac{(1+g)^{n}}{(1+i)^{n}}}{i-g} & =\lim _{n \rightarrow \infty} D \frac{1-\left(\frac{1+g}{1+i}\right)^{n}}{i-g} \stackrel{i>g}{=} \\
& =\frac{D}{i-g}
\end{aligned}
$$

Contudo, sendo $g \geq i$, a soma (3.2) cresce a cada nova parcela e o resultado final é que avaliação do preço da ação tende ao infinito. Esse resultado retoma a característica principal do paradoxo de São Petersburgo na qual nenhum jogador racional estaria disposto a pagar um valor infinito para participar.

Para Durand, os mesmos motivos que levaram autores que o precederam a explicar as razões das discrepâncias típicas do paradoxo, e apresentarem valores mais próximos àqueles que as pessoas em geral estão dispostas a pagar, são válidos também no processo de formação de preços no mercado acionário. Inúmeras razões são apresentadas por ele no sentido de dissuadir qualquer investidor de pagar preços exorbitantes por papéis de empresas que supostamente apresentam forte crescimento.

Uma sugestão de Durand no sentido de tornar o processo de precificação mais realista é, por exemplo, adotar mecanismos que permitam a provisão de parte dos dividendos de tal sorte que seja possível diminuir (ou mesmo cessar) a taxa de crescimento $g$ dos mesmos; ou ainda, diminuir a utilidade marginal de grandes dividendos usando funções subjetivas semelhantes às adotados por Bernoulli[1] e Cramer[5]; ou seguir os procedimentos descritos por Clendenin-Cleave[3] e trabalhar com taxas de desconto variáveis $i_{k}$ que permitam adotar maiores descontos para dividendos mais remotos e menos significativos ou prováveis para o investidor; e, por fim, evidentemente aplicar todas essas sugestões combinadas.

Em Szérkely-Richards[15] os autores, ao realizar uma releitura do artigo de Durand[7], encontraram novas circunstâncias conjunturais que para eles 
poderiam muito bem ser evitadas caso maior atenção tivesse sido direcionada ao problema do paradoxo de São Petersburgo aplicado à avaliação do preço das ações. A chamada exuberância irracional, ${ }^{5}$ particularmente observada na valorização desenfreada de ações de alta tecnologia ${ }^{6}$ na segunda metade dos anos 1990, veio finalmente cobrar a imprudência dos analistas financeiros, com severas perdas aos investidores que acreditaram em suas avaliações, a partir de 10 de março de 2000 (quando o índice Nasdaq, da bolsa eletrônica americana homônima principalmente utilizada para negociação de ativos de tecnologia, o chamado "novo mercado", atingiu o seu culme histórico e teve forte queda em seguida). Esse evento ficou conhecido como o estouro da bolha das empresas ponto-com.

\footnotetext{
${ }^{5}$ Termo cunhado a partir do discurso do ex-presidente do Federal Reserve (banco central americano), Alan Greenspan, feito em dezembro de 1996 durante o jantar anual e palestra de Francis Boyer do American Enterprise Institute. Referências em Greenspan[10].

${ }^{6}$ Esse movimento de valorização deve-se em grande medida às empresas de alguma forma ligadas à comercialização de bens e serviços via internet. Na esteira das expectativas de mudança no paradigma de funcionamento dos mercados, principalmente devida ao processo de popularização da grande rede, a capacidade de avaliar racionalmente teria ficado prejudicado segundo Greenspan[10].
} 


\section{Capítulo 4}

\section{O paradoxo segundo a moderna Teoria de Probabilidades}

\subsection{Hipóteses necessárias}

Retomando-se a definição de jogo honesto apresentada em (1.1.3) tinha-se que $X_{k}$ representava uma variável aleatória a ser interpretada como o ganho (positivo ou negativo) do jogador. Considerou-se naquela seção, sem maiores julgamentos, que o valor $\mu=E\left(X_{k}\right)$ tinha o poder de representar um preço justo de entrada em qualquer jogo que apresentasse tal ganho médio, uma idéia inserida até então intuitivamente. Contudo, nesse momento faz-se necessário formalizar as hipóteses que viabilizam a classificação de um jogo, nos moldes do paradoxo de São Petersburgo, como "honesto":

- (H1) O jogador deve ser dotado de capital ilimitado;

- (H2) O jogador manter-se-á jogando várias tentativas do mesmo jogo, não tendo direito a parar nem mesmo numa situação em que isso o favoreça;

- (H3) Antes mesmo da primeira tentativa do jogador, a banca terá determinado um limite fixo $n$ de tentativas abertas ao jogador para 
conseguir obter a primeira face cara, o mesmo não será alterado enquanto o jogo avança e, caso a cara não apareça até $n$, o jogador nada recebe ${ }^{1}$.

Não fosse por (H1) o jogador correria o risco de quebrar e a formulação do problema ${ }^{2}$ deveria ser outra. Igualmente, (H2) busca limitar o fim prematuro do jogo.

Cabe à hipótese (H3) determinar, mesmo que longínquo, um fim para o jogo. Se não houvesse um fim pré-estabelecido, o jogo não possuiria esperança matemática e adotar o valor $\mu$ para a mesma não faria o menor sentido ${ }^{3}$. A soma $S_{n}=X_{1}+\cdots+X_{n}$ deverá representar, portanto, o ganho acumulado do jogador nas $n$ tentativas que lhe foram concedidas. Também pelo fato de existir $\mu=E\left(X_{k}\right)$, as condições necessárias (mas não suficientes) para poder-se aplicar a Lei dos Grandes Número estão verificadas. Intuitivamente a lei dos grandes números significa que:

"Para $n$ suficientemente grande, a diferença $S_{n}-\mu$ tenderá a ser pequena em relação a $n "$.

Suponha-se que o preço pago para entrar no jogo seja $\mu^{\prime}$, então $n \mu^{\prime}$ representa o valor acumulado das taxas de entrada, e, $S_{n}-n \mu^{\prime}$ representará o ganho acumulado líquido. Quando a taxa de entrada $\mu^{\prime}$ for menor do que $\mu$, o jogador muito provavelmente terá um ganho positivo e sua magnitude será de $n\left(\mu-\mu^{\prime}\right)$. Pelo mesmo motivo, a perda será praticamente certa quando $\mu^{\prime}>\mu$. Em suma, $\mu^{\prime}<\mu$ é favorável ao jogador, enquanto $\mu^{\prime}>\mu$ é desfavorável.

A concluir do argumentado acima, tem-se que a definição de "jogo honesto" é melhor formalizada num contexto em que seja válida a lei dos grandes números.

\footnotetext{
${ }^{1}$ Jogo semelhante ao apresentada em (2.11), com a diferença que, nessa versão, o apostador nada ganha se o jogo chegar ao fim.

${ }^{2} \mathrm{O}$ tratamento desses casos é conhecido em probabilidades como o problema da ruína do jogador.

${ }^{3}$ A rigor o conceito de "jogo honesto" não se aplica a formulação original do paradoxo de São Petersburgo, em que a média dos ganhos vai para o infinito.
} 


\subsection{A lei dos grandes números (LGN)}

Formalmente define-se a lei da seguinte maneira. Seja $\left\{X_{k}\right\}$ uma sequência de variáveis aleatórias discretas independentes e identicamente distribuídas (i.i.d.), se a esperança $\mu=E\left(X_{k}\right)$ existe, então, para qualquer $\epsilon>0$, à medida que $n \rightarrow \infty$ tem-se:

$$
\operatorname{Pr}\left\{\left|\frac{X_{1}+\cdots+X_{n}}{n}-\mu\right|>\epsilon\right\} \rightarrow 0
$$

em palavras, significa que a probabilidade da diferença, entre a média dada por $S_{n} / n$ e a esperança $\mu$, ser maior que uma constante $\epsilon$ (tão pequena quanto se queira), tende a zero.

Convergência da Média Amostral para o Valor Esperado

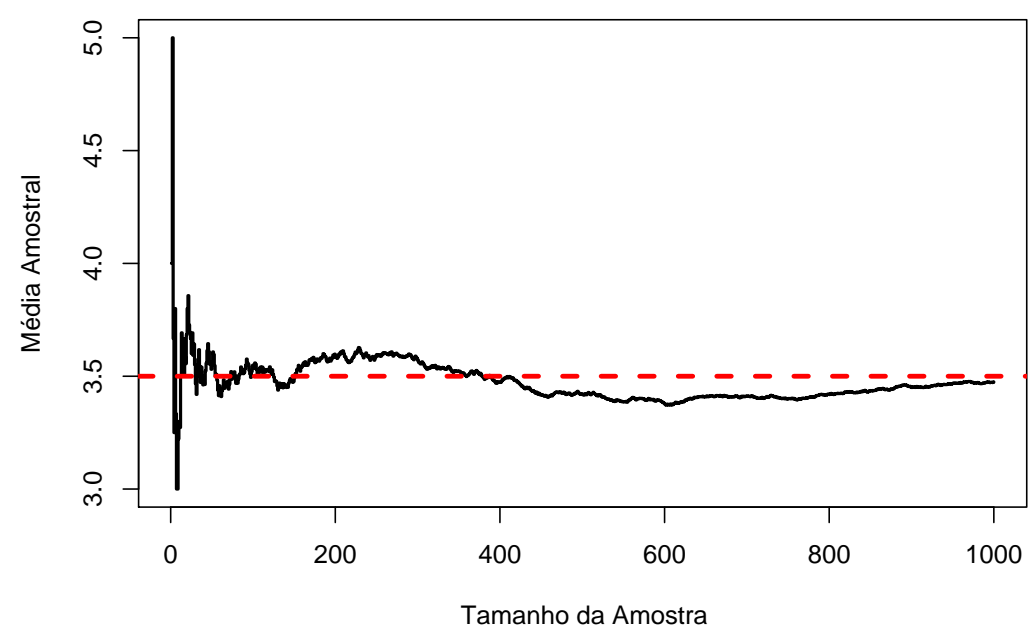

\begin{tabular}{|c|c|c|c|c|c|c|c|}
\hline Número da Observação & $\mathbf{1}$ & $\mathbf{2}$ & $\mathbf{3}$ & $\mathbf{1 0}$ & $\mathbf{1 0 0}$ & $\mathbf{5 0 0}$ & $\mathbf{1 0 0 0}$ \\
\hline Face Observada & 4 & 6 & 1 & 4 & 4 & 1 & 5 \\
Média Amostral & 4 & 5 & 3.6667 & 3.3 & 3.55 & 3.418 & 3.475 \\
\hline
\end{tabular}

Na seção (1.1.2) apresentou-se o exemplo de um dado de seis faces honesto (isto é, um dado que possui probabilidade $1 / 6$ de ocorrência de qualquer uma de suas faces num determinado lançamento) para explicar intuitivamente o conceito de valor esperado. Como dito anteriormente, uma variável 
aleatória $X$ que venha representar um lançamento desse dado tem valor esperado $E(X)=3,5$. No experimento representado acima, um dado desse tipo foi lançado 1.000 vezes. Note-se como à medida que o tamanho da amostra cresce, há uma tendência de diminuir a diferença absoluta entre a Média Amostral e o valor esperado da distribuição. Tal fato é devido à lei dos grandes números (LGN).

\subsubsection{Prova da LGN pela desigualdade de Chebyshev}

Para o caso em que existe $\sigma^{2}=\operatorname{Var}\left(X_{k}\right)$, é suficiente o uso da Desigualdade de Chebyshev para provar a lei dos grandes números. Seja $Y$ uma variável aleatória com média $\mu_{Y}=0$ e variância $\sigma_{Y}^{2}=\operatorname{Var}(Y)$ então vale:

$$
\operatorname{Pr}\{|Y|>t\} \leq \frac{\sigma_{Y}^{2}}{t^{2}}
$$

Sem perda de generalidade, fazendo-se a troca de variáveis em que a $Y=$ $X_{1}+\cdots+X_{n}-n \mu$, e, portanto, sendo a mesma centrada em zero e com variância determinada $\sigma_{Y}^{2}=n \sigma^{2}$, vale de (4.2):

$$
\operatorname{Pr}\{|Y|>t\} \leq \frac{n \sigma^{2}}{t^{2}}
$$

tomando-se $t=n \epsilon$ :

$$
\begin{aligned}
\operatorname{Pr}\{|Y|>n \epsilon\} & \leq \frac{n \sigma^{2}}{n^{2} \epsilon^{2}} \\
\operatorname{Pr}\{|Y|>n \epsilon\} & \leq \frac{\sigma^{2}}{n \epsilon^{2}} \\
\operatorname{Pr}\left\{\left|X_{1}+\cdots+X_{n}-n \mu\right|>n \epsilon\right\} & \leq \frac{\sigma^{2}}{n \epsilon^{2}} \\
\operatorname{Pr}\left\{\left|\frac{X_{1}+\cdots+X_{n}}{n}-\mu\right|>\epsilon\right\} & \leq \frac{\sigma^{2}}{n \epsilon^{2}}
\end{aligned}
$$


então, se $n \rightarrow \infty$ :

$$
\operatorname{Pr}\left\{\left|\frac{X_{1}+\cdots+X_{n}}{n}-\mu\right|>\epsilon\right\} \rightarrow 0
$$

\section{Prova da desigualdade de Chebyshev}

A desigualdade de Chebyshev pode ser provada diretamente através da desigualdade de Markov que é da seguinte maneira determinada. Seja $Z$ uma variável aleatória com média $\mu_{Z}=E(Z)$, então vale:

$$
\operatorname{Pr}\{|Z| \geq t\} \leq \frac{E(|Z|)}{t}
$$

Sem perda de generalidade, fazendo-se a troca de variáveis em que a $Z=$ $\left(Y-\mu_{Y}\right)$, e, como a esperança de $Z$ existe, vale de (4.3):

$$
\begin{aligned}
\operatorname{Pr}\left\{\left|Y-\mu_{Y}\right| \geq t\right\} & \leq \frac{E\left(\left|Y-\mu_{Y}\right|\right)}{t} \\
\operatorname{Pr}\left\{\left|Y-\mu_{Y}\right|^{2} \geq t^{2}\right\} & \leq \frac{E\left(\left|Y-\mu_{Y}\right|^{2}\right)}{t^{2}} \\
\operatorname{Pr}\left\{\left|Y-\mu_{Y}\right|^{2} \geq t^{2}\right\} & \leq \frac{\sigma_{Y}^{2}}{t^{2}}
\end{aligned}
$$

Lembrando que o evento $\left\{\left|Y-\mu_{Y}\right|^{2} \geq a^{2}\right\}$ só corre se, e somente se, $\{\mid Y-$ $\mu_{Y} \mid \geq a$ \} ocorre e ,definido $\mu_{Y}$ nulo, como feito em (4.2), tem-se:

$$
\operatorname{Pr}\{|Y|>t\} \leq \frac{\sigma_{Y}^{2}}{t^{2}}
$$

\section{Prova da desigualdade de Markov}

Seja $Z$ uma variável aleatória, com $E(|Z|)$ definida, tem-se que para $t>0$, define-se a função indicadora $I_{|Z| \geq t}$ por:

$$
I_{|Z| \geq t}= \begin{cases}1 & , \text { se }|Z| \geq t \\ 0 & , \text { caso contrário. }\end{cases}
$$


segue que:

$$
\begin{aligned}
I_{|Z| \geq t} & \leq \frac{|Z|}{t} \\
E\left(I_{|Z| \geq t}\right) & \leq \frac{E(|Z|)}{t}
\end{aligned}
$$

Como $E\left(I_{|Z| \geq t}\right)=P|Z| \geq t$ :

$$
\operatorname{Pr}\{|Z| \geq t\} \leq \frac{E(|Z|)}{t}
$$

\subsubsection{Prova da LGN para quando a variância não é finita}

Essa prova, apresentada em Feller $[9]^{4}$ e escrita com muito mais detalhes entre cada passagem do que a original, é especialmente importante porque o mecanismo utilizado para realizá-la, o Método do Truncamento, será usado mais a frente para provar que é possível construir um sistema de taxas de entrada que tornam o jogo de São Petersburgo "honesto" no sentido dado pelos clássicos (como Bernoulli) e que respeita o formalismo da LGN.

Sem perda de generalidade, considere-se $\left\{X_{k}\right\}$ uma sequência de variáveis aleatórias discretas i.i.d. com média nula e seja $\delta>0$ uma constante positiva a ser determinada a posteriori. Para cada $n$, define-se $n$ pares de variáveis aleatórias como segue:

$$
\begin{array}{lcc}
U_{k}=X_{k}, & V_{k}=0 & \text { se }\left|X_{k}\right| \leq \delta n \\
U_{k}=0, & V_{k}=X_{k} & \text { se }\left|X_{k}\right| \geq \delta n
\end{array}
$$

\footnotetext{
${ }^{4}$ William Feller(1906-1970) foi um matemático croata-americano especialista em teoria da probabilidade. Inúmeros tópicos em probabilidade levam o seu nome: Processo de Feller, Teste de Explosão de Feller, Movimento Feller-Brown, Propriedade de Feller e Teorema de Lindberg-Feller. Seus livros foram considerados grandes responsáveis pelo processo de popularização do ensino de probabilidades e entre os melhores do século XX.
} 
em que $k=1, \cdots, n$. Dessa definição resulta que:

$$
X_{k}=U_{k}+V_{k}
$$

Para provar-se a LGN é suficiente provar que, para qualquer $\epsilon>0$ dado, quando $n \rightarrow \infty$ observa-se:

$$
\operatorname{Pr}\left\{\left|U_{1}+\cdots+U_{n}\right|>(1 / 2) \epsilon n\right\} \rightarrow 0
$$

e

$$
\operatorname{Pr}\left\{\left|V_{1}+\cdots+V_{n}\right|>(1 / 2) \epsilon n\right\} \rightarrow 0
$$

Pela definição (4.5) $U_{1}$ está limitada a $\delta n$. Isso permite afirmar que existe o segundo momento de $U_{1}$ e ainda:

$$
\begin{aligned}
& E\left(U_{1}^{2}\right)=E\left(\left|U_{1}\right|^{2}\right) \\
& E\left(U_{1}^{2}\right)=\sum_{j}\left|u_{j}\right| \cdot\left|u_{j}\right| \cdot f\left(u_{j}\right) \leq \sum_{j} \delta n \cdot\left|u_{j}\right| \cdot f\left(u_{j}\right) \leq \sum_{j} \delta n \cdot\left|x_{j}\right| \cdot f\left(x_{j}\right) \\
& E\left(U_{1}^{2}\right) \leq \delta n E\left(\left|X_{1}\right|\right)
\end{aligned}
$$

Uma vez que as variáveis $U_{1}, \ldots, U_{n}$ são, por hipótese, i.i.d. tem-se que:

$$
\begin{aligned}
\operatorname{Var}\left(U_{1}+\cdots+U_{n}\right) & \stackrel{\text { iid }}{=} n \operatorname{Var}\left(U_{1}\right)=n\left[E\left(U_{1}^{2}\right)-E^{2}\left(U_{1}\right)\right] \\
n\left[E\left(U_{1}^{2}\right)-E^{2}\left(U_{1}\right)\right] & \leq n E\left(U_{1}^{2}\right) \stackrel{(4.9)}{\leq} \delta n^{2} E\left(\left|X_{1}\right|\right)
\end{aligned}
$$

Vale ressaltar que, devido à definição (4.5), quando $n \rightarrow \infty$ :

$$
E\left(U_{1}\right) \rightarrow E\left(X_{1}\right)=0
$$

Como vale a relação:

$$
E\left[\left(U_{1}+\cdots+U_{n}\right)^{2}\right]=\operatorname{Var}\left(U_{1}+\cdots+U_{n}\right)+E^{2}\left(U_{1}+\cdots+U_{n}\right)
$$


Tomando $b=E^{2}\left(U_{1}+\cdots+U_{n}\right)$ e aplicando-se (4.11), segue que, para $n$ suficientemente grande:

$$
E\left[\left(U_{1}+\cdots+U_{n}\right)^{2}\right]=\operatorname{Var}\left(U_{1}+\cdots+U_{n}\right)+b
$$

com $b \rightarrow 0$ para $n$ suficientemente grande. Agora aplicando-se (4.10) à equação acima, pode-se afirmar que:

$$
E\left[\left(U_{1}+\cdots+U_{n}\right)^{2}\right] \leq 2 \delta n^{2} E\left(\left|X_{1}\right|\right)
$$

Finalmente, usando a equação acima e a desigualdade de Chebyshev (4.2), tem-se para quando $n \rightarrow \infty$ :

$$
\begin{aligned}
& \operatorname{Pr}\left\{U_{1}+\cdots+U_{n}>(1 / 2) \epsilon n\right\} \stackrel{(4.2)}{\leq} \frac{2 \delta n^{2} E\left(\left|X_{1}\right|\right)}{(1 / 4) \epsilon^{2} n^{2}} \\
& \operatorname{Pr}\left\{U_{1}+\cdots+U_{n}>(1 / 2) \epsilon n\right\} \leq \frac{8 \delta E\left(\left|X_{1}\right|\right)}{\epsilon^{2}}
\end{aligned}
$$

Escolhendo $\delta$ pequeno o suficiente, tem-se que o lado direito da inequação pode ser tão pequeno quanto se deseje, então (4.7) é verdadeiro.

Com relação a (4.8):

$$
\begin{array}{ll}
\operatorname{Pr}\left\{V_{1}+\cdots+V_{n} \neq 0\right\} & \leq \operatorname{Pr}\left\{V_{1} \neq 0\right\}+\cdots+\operatorname{Pr}\left\{V_{n} \neq 0\right\} \\
\operatorname{Pr}\left\{V_{1}+\cdots+V_{n} \neq 0\right\} & \leq n \operatorname{iid}\left\{V_{1} \neq 0\right\}
\end{array}
$$

o evento $\left\{V_{1}+\cdots+V_{n} \neq 0\right\}$ é o mesmo que afirmar que pelo menos um dos $V_{k}$ 's é não-nulo. Como os eventos não são mutuamente exclusivos, vale a inequação acima. Para $\delta>0$ arbitrário, usando(4.5) tem-se:

$$
\begin{aligned}
& \operatorname{Pr}\left\{V_{1}+\cdots+V_{n} \neq 0\right\}=n \operatorname{Pr}\left\{\left|X_{1}\right|>\delta n\right\} \stackrel{i i d}{=} \sum_{\left|x_{j}\right|>\delta n} 1 \cdot f\left(x_{j}\right) \\
& \operatorname{Pr}\left\{V_{1}+\cdots+V_{n} \neq 0\right\} \leq \frac{1}{\delta n} \sum_{\left|x_{j}\right|>\delta n}\left|x_{j}\right| \cdot f\left(x_{j}\right)
\end{aligned}
$$


Uma vez que o somatório acima tende a zero quando $n \rightarrow \infty$, o lado esquerdo da inequação (4.16) vai a zero. Sendo essa última afirmação mais forte do que (4.8) conclui-se a prova.

\subsection{A lei dos grandes números (LGN) apli- cada ao paradoxo}

\subsubsection{Prova da aplicabilidade}

O objetivo dessa seção é provar que o conceito de "jogo honesto" (ou justo) pode ser aplicado ao paradoxo de São Petersburgo se inseridas novas restrições, isto é, as condições necessárias determinadas anteriormente em (4.1).

Seja $\left\{X_{k}\right\}$ uma sequência de variáveis aleatórias i.i.d. de média $\mu>0$, define-se que $S_{n}=X_{1}+\cdots+X_{n}$ e $e_{n}$, sendo esse última a taxa de entrada acumulada.

Uma maneira diferente de verificar a lei dos grandes números aplicada ao jogo de Petersburgo é observar o comportamento da razão $S_{n} / e_{n}$ para quando $n \rightarrow \infty$. Se a razão converge em probabilidade para 1 , significa que a LGN é válida, isto é:

$$
\operatorname{Pr}\left\{\left|\frac{S_{n}}{e_{n}}-1>\epsilon\right|\right\} \rightarrow 0
$$

para $\epsilon>0$ arbitrariamente determinado.

A afirmação (4.18) é completamente análoga à lei dos grandes números definida em (4.1), quando se determina $e_{n}=n \mu$.

Abaixo encontra-se a demonstração de que o jogo de Petersburgo tornase "honesto" quando a restrição adicional imposta é que a taxa de entrada acumulada $e_{n}=n \log n$, em que $\log n$ é um logaritmo na base 2 . Vale lembrar que, no contexto do jogo de Petersburgo, $S_{n}$ representa os ganhos acumulados de acordo com enunciado original do mesmo. 
Novamente utilizando o Método de Truncamento, porém, dessa vez definindo as variáveis $U_{k}$ e $V_{k}$ da seguinte forma:

$$
\begin{array}{lcl}
U_{k}=X_{k}, & V_{k}=0 & \text { se } X_{k} \leq n \log n \\
U_{k}=0, & V_{k}=X_{k} & \text { se } X_{k}>n \log n
\end{array}
$$

Então:

$$
\begin{aligned}
\operatorname{Pr}\left\{\left|\frac{S_{n}}{e_{n}}-1\right|>\epsilon\right\} \leq \operatorname{Pr}\left\{\mid U_{1}+\cdots+\right. & \left.U_{n}-e_{n} \mid>\epsilon e_{n}\right\} \\
& +P\left\{V_{1}+\cdots+V_{n} \neq 0\right\}
\end{aligned}
$$

uma vez que o evento à esquerda não pode ocorrer a menos que um dos eventos da direita ocorra.

Para verificar (4.20) é suficiente provar que:

$$
\operatorname{Pr}\left\{\left|U_{1}+\cdots+U_{n}-n \log n\right|>\epsilon n \log n\right\} \rightarrow 0
$$

Se $\mu_{n}=E\left(U_{k}\right)$ e $\sigma_{n}^{2}=\operatorname{Var}\left(U_{k}\right)$, essas quantidades dependerão de $n$, mas são comuns a $U_{1}, \cdots, U_{n}$. Se $r$ é o maior inteiro tal que $2^{r} \leq n \log n$, então $\mu_{n}=r$ e para $n$ suficientemente grande tem-se:

$$
\log n<\mu_{n} \leq \log n+\log \log n
$$

Da mesma forma:

$$
\sigma_{n}^{2} \leq E\left(U_{k}^{2}\right)=2+2^{2}+\cdots+2^{r}<2^{r+1} \leq 2 n \log n
$$

Como a soma $U_{1}+\cdots+U_{n}$ tem média $n \mu_{n}$ e variância $n \sigma_{n}^{2}$, tem-se da Desigualdade de Chebyshev:

$$
\operatorname{Pr}\left\{\left|U_{1}+\cdots+U_{n}-n \mu_{n}\right|>\epsilon n \mu_{n}\right\} \leq \frac{n \sigma_{n}^{2}}{\epsilon^{2} n^{2} \mu_{n}^{2}}<\frac{2}{\epsilon^{2} \log n} \rightarrow 0
$$


De (4.22) $\mu_{n} \approx \log n$ e portanto (4.24) é equivalente a (4.21).

\subsubsection{Um jogo "honesto" mas com perdas crescentes ao jogador}

Como visto na seção anterior, o conceito de "jogo honesto" só é aplicável a jogos em que a LGN seja aplicável. Para a versão do paradoxo em que a LGN é aplicável concluiu-se que $\mu^{\prime}<\mu$ é favorável ao jogador, enquanto $\mu^{\prime}>\mu$ é desfavorável. Seja $\left\{X_{k}\right\}$ uma sequência de variáveis aleatórias i.i.d. de média $\mu$ e definindo-se $S_{n}=X_{1}+\cdots+X_{n}$, tem-se que para $\epsilon>0$ e $n \rightarrow \infty$, a LGN pode ser rescrita como:

$$
\operatorname{Pr}\left\{\left|S_{n}-n \mu\right|<\epsilon n\right\} \rightarrow 1
$$

Entretanto, em Feller[8] o autor alerta para o fato que mesmo um jogo considerado com o preço justo, em que taxa de entrada é fixa e vale $\mu^{\prime}=\mu$, o jogador pode sofrer uma perda, $L_{n}=n \mu-S_{n}$, crescente e com ordem de magnitude $\frac{n}{(\log n)^{\eta}}$, onde $\eta>0$ é tão pequeno quanto se queira. No artigo mencionado, Feller prova que é possível ter-se:

$$
\operatorname{Pr}\left\{n \mu-S_{n}>(1-\epsilon) \frac{n}{(\log n)^{\eta}}\right\} \rightarrow 1
$$




\section{Capítulo 5}

\section{Conclusão}

Lembrando que o presente trabalho foi dividido em três partes principais: a primeira, em que foram apresentadas as principais tentativas históricas de solucionar o paradoxo; a segunda, em que se mostrou uma aplicação prática do paradoxo; e a terceira, em que o paradoxo é submetido ao rigor da moderna Teoria de Probabilidades. As seguintes conclusões puderam ser extraídas:

A primeira parte do estudo foi importante para mostrar a evolução do precário pensamento dos probabilistas clássicos com relação uma séries de conceitos como probabilidade, valor esperado e, até mesmo, tratamento de operações com valores infinitos positivos e negativos. Uma crítica que talvez caiba a Bernoulli, mesmo considerando as limitações a que todos os probabilistas daquela época estavam sujeitos, é, por exemplo, a hipótese de que a única função utilidade citada, a que faria o maior sentido possível para expressar o comportamento humano seria $U(X)=\log (X)$. A Menger atribui-se a capacidade de perceber que para funções-utilidade ilimitadas sempre poderse-ia criar um "super-paradoxo" que traria de volta o problema da esperança infinita, porém, mesmo com o todo o ferramental dos teoremas de limites que já lhe estavam disponíveis, pouco contribui para formalização dos conceitos adjacentes ao paradoxo.

Por fim, na terceira parte, expos-se que coube a Feller desempenhar o 
papel de formalizar e identificar melhor as hipóteses (como a introdução da Lei Fraca dos Grandes Números para melhor caracterizar o conceito clássico de jogo honesto) assumidas para que o paradoxo pudesse ser analisado. Sem criticar diretamente a possibilidade da esperança do jogo ir para o infinito, quando $n$ vai para infinito, mas sim baseando a sua crítica ao fato que o preço justo não é necessariamente aquele dado pela esperança do jogo, mostrou que não se pode confiar na intuição ao se lidar com quantidades que vão ao infinito. Com essa abordagem o probabilista croata inaugurou uma nova fase nos estudos do problema de São Petersburgo.

A partir dos trabalhos publicados por Feller, a maioria dos artigos que apresentam novidades realmente relevantes como Csörgõ-Csáki-Berkes[6] seguem essa linha inaugurada por ele.

Uma proposta de novos estudos seria sintetizar essa linha de trabalhos novos e tornar suas considerações mais facilmente demonstráveis. 


\section{Referências Bibliográficas}

[1] Bernoulli, D. Exposition of a new theory on the measurement of risk. Commentarii Academiae Scientiarum Imperialis Petropolitanae $V$ (1783). Translated by Sommer, L., Econommetrica 22 (1954), 23-36.

[2] Casella, G., And Berger, R. Statistical Inference, 2nd ed. Duxbury Advanced Series, 2002.

[3] Clendenin, J. C., And Cleave, M. V. Growth and common stock values. Jornal of Finance IX (1783), 33-35.

[4] Copeland, T., Koller, T., And Murrin, J. Valuation-Measuring and Managing the Value of Companies, 3rd ed. McKinsey \& Company, Inc., 2001.

[5] Cramer, G. Letter to N. Bernoulli. Ref Bernoulli (1728). Fully published in Econommetrica 22 (1954), 23-36.

[6] Csörgõ, S., Csáki, E., And Berkes, I. Almost sure limit theorems for the St. Petersburg game. Statistics 8 P Probability Letters, 45 (1999), $23-30$.

[7] Durand, D. Growth stocks and the Petersburg paradox. The Journal of Finance, 12 (1957), 348-363.

[8] Feller, W. Note on the law of large numbers and fair games. Annals of Mathematical Statistics, 16 (1945), 301-304.

[9] Feller, W. An Introduction to Probability Theory and Its Applications Vol I, 3rd ed. New York: Wiley, 1968. 
[10] Greenspan, A. The challenge of central banking in a democratic society. The Federal Reserve Board - Remarks (1996). At the Annual Dinner and Francis Boyer Lecture of The American Enterprise Institute for Public Policy Research, Washington, D.C.

[11] James, B. R. Probabilidade: Um Curso em Nível Intermediário, 2nd ed. IMPA: Instituto Nacional de Matemática Pura e Aplicada, 2002.

[12] Magalhães, M. N. Probabilidade e Variáveis Aleatórias, 1st ed. IMEUSP: Instituto de Matemática e Estatistica, Universidade de São Paulo, 2004.

[13] Menger, K. The role of uncertainty in Economics. Essays in Mathematical Economics in Honor of Oskar Morgenstern, 16 (1967). Published by Princeton: Princeton University Press.

[14] Samuelson, P. A. St. Petersburg paradoxes: Defanged, dissected, and historically described. Journal of Economic Literature, 15 (1977), 24-25.

[15] SzÉrkely, G. J., And Richards, D. S. P. The St Petersburg paradox and the crash of high-tech stocks in 2000. American Statistical Association 58, 3 (2004), 225-231.

[16] Williams, J. B. The Theory of Investment Value. Cambridge, Mass.: Harvard University Press, 1938. 